\title{
A flow-to-equity approach to coordinate supply chain network planning and financial planning with annual cash outflows to an institutional investor
}

\author{
Martin Steinrücke ${ }^{1} \cdot$ Wolfgang Albrecht ${ }^{1}$
}

Received: 21 August 2015/Accepted: 13 June 2016/Published online: 29 June 2016

(C) The Author(s) 2016. This article is published with open access at Springerlink.com

\begin{abstract}
A common side effect of cross-linked global economies is that wellpositioned middle class companies are acquired by institutional investors, which formulate unreasonable return expectations in many cases. As a consequence, the resulting payouts are often not in line with business operations so that even world market leaders get into trouble or close down. In this context, we consider the case of a sanitary company, which had to manage the described situation after a business takeover. In order to coordinate the annual cash outflows to the investor with intraorganizational supply chain planning and financial planning, we propose a mixedinteger non-linear programming model that is based on the flow-to-equity discounted cash flow method. The objective is to maximize the present value of equity while determining annual cash outflows to the institutional investor during his engagement. As the decisions of the investor during his engagement influence possible operations of the company after his engagement, the residual value of equity (that influences the selling price) is taken into account. The modeling is based on cash flow series, which result from supply chain operations and restructuring on the one hand, and from financial transactions on the other. Financing is characterized by interest rates depending on the time period the credit starts, the credit period, the debt limit of the company and the current total debt. As the latter is a result of the optimization, non-linearity arises. Nevertheless, both the expected demand scenario and further randomly generated demand scenarios of the sanitary company could be solved to the optimum with the commercial optimization package GAMS
\end{abstract}

Martin Steinrücke

martin.steinruecke@uni-greifswald.de

Wolfgang Albrecht

wolfgang.albrecht@uni-greifswald.de

1 Faculty of Law and Economics, University of Greifswald, Friedrich-Loeffler-Str. 70, 17489

Greifswald, Germany 
23.8/SCIP 2.1.1 within acceptable computation times, if capacity profiles are assigned to the locations to depict feasible and/or preferred capacity developments.

Keywords Company takeover · Flow-to-equity method · Annual cash outflows to the investor - Supply chain design - Capacity profiles · Mixedinteger non-linear programming

\section{Introduction}

The approach and the case study proposed in this paper are motivated by a German sanitary fittings producer that was acquired by a private equity company. The oldestablished manufacturer, traded as a joint-stock, was characterized by ongoing expansion and thus developed to a global leader in the market segment. After 10 years, and even though the company was still growing, the owners decided to sell it to an institutional investor. The new owner started to coordinate the whole business by appointing a holding company that claimed massive annual cash outflows from the related supply chain (SC). This led to restructuring activities including the need to cut down costs and staff. A resulting decline in sales and profits began to risk the company's continued existence. The reasons for the business problems were obvious. The investor considered the acquisition as pure financial investment focusing only on the expected return. Existing efficient network structures including locations, capacities and business partner relations as well as the supply chain operations were disregarded, as a counterproductive decoupling of decisions could be observed in this case.

A quantitative model suitable for solving the aforementioned problem must meet the following requirements: First, it must be applicable to intra-organizational supply chain structures (Morash and Clinton 1998; Flynn et al. 2011; also referred to as company-wide SC, Longinidis and Georgiadis 2011) with centralized decisions that are controlled by an institutional investor after the company takeover. Due to the investor's multiannual engagement, both long-term adjustments of the supply chain design and resulting changes of supply chain operations must be taken into account. Therefore, discrete time modeling (Van Roy and Erlenkotter 1982) should be preferred. As the prevention of insolvency during the engagement requires liquidity compensation in each period, the modeling must combine supply chain planning and financial planning (Shapiro 2004) by taking cash flow series and financing instruments into account. In particular, a flow-to-equity (FTE) approach is applicable in our case, as it measures the cash available to be paid out to the investor after meeting reinvestment needs (Damodaran 2012). As relevant for the amounts actually returned, the underlying equity approach exclusively focuses on cash flows after effective tax payments.

The article is structured as follows: Section 2 gives a literature review of other relevant contributions revealing that the presented optimization model offers a conceptual approach to solve the mentioned problem and extends the existing research in the treated field. The mathematical formulation based on alternatively selectable capacity profiles is presented in Sect. 3. A model variant using capacity 
levels is depicted in Sect. 4. The case study of the aforementioned sanitary company is presented in Sects. 5 and 6. To discuss the consequences of fluctuations in demand, uncertainties in the determination of discounting rates, and the consideration of sustainability requirements, we use a scenario analysis in Sect. 7.

\section{Literature review}

According to the aforementioned requirements, the literature review covers the integration of different business levels controlled by the institutional investor on the one hand, and the integration of supply chain planning and financial planning on the other.

In general, supply chain management covers facility location planning, capacity planning, supplier and sales market selection as well as supply chain operations. The following approaches contain modeling elements with relevance for the problem described, but neglect the financial domain: Configuration changes (opening and closing of plants and warehouses) refer to facility location problems, e.g., Hinojosa et al. (2000) and Canel and Khumawala (2001). Melo et al. (2005) analyze connections between the openings and closings of facilities and the relocation of capacities. Further approaches in the context of facility location planning and supply chain management are reviewed by Melo et al. (2009). Moreover, the planning should consider external partners or markets at the edges of the supply chain. Approaches for the supplier selection are found in Jayaraman et al. (1999) and Amid et al. (2009). A literature review of mathematical approaches for supplier evaluation and selection is given by Ho et al. (2010). Problems associated with the sales market selection are described by Taaffe and Geunes (2004) and Taaffe et al. (2008). The optimization of material flows resulting from procurement, production, storage and distribution within supply chains is modeled by Arntzen et al. (1995), Ouhimmou et al. (2008), Rong et al. (2011), Baud-Lavigne et al. (2012), Steinrücke and Jahr (2012) and Steinrücke and Albrecht (2016).

The adjustment of limited capacities in annual periods to depict alternative facility configurations realistically requires the selection among a discrete set of alternatives (Amrani et al. 2011). In literature, the latter are usually modeled by capacity levels. Amiri (2006) introduces capacity levels available to potential warehouses and plants and resolves substantial drawbacks of previous strategic approaches. These capacity levels affect the maximum production or throughput at the facilities and the fixed costs for operating within the entire planning horizon, which is not subdivided into time periods. The same applies to the fuzzy multiobjective model that has been developed by Selim and Ozkarahan (2008) for the SC distribution network design problem. Within their two-echelon SC network design problem in a deterministic single-period multi-commodity context, Sadjady and Davoudpour (2012) model alternative capacity levels for warehouses and plants, and additionally provide an algorithm for their determination. Babazadeh et al. (2013) apply the selection of capacity levels to locations of three different stages (plants, warehouses, cross-docks) of their supply chain network. Correia et al. (2013) model a finite set of capacity levels for product families that is available at 
each potential location. According to their multi-period formulation, the resulting capacity alternatives within the time periods are related to technology selection. Keyvanshokooh et al. (2013) include capacity levels in a model applicable to integrated forward/reverse logistics network design, as they assign them to production/recovery centers, distribution centers and collection centers. Within the multi-objective stochastic model for a forward/reverse logistic network design by Ramezani et al. (2013), the opening of plants, distribution centers, collection centers, hybrid processing facilities and disposal centers is connected to alternative capacity levels. Azad and Davoudpour (2013) use capacity levels for the distribution centers within their stochastic distribution network designing problem to route the vehicles to serve the customers more flexibly. Furthermore, they found out that capacity utilization increases to a higher level in this way. A set of capacity levels for distribution centers is modeled by Ashtab et al. (2014) within their non-linear optimization model for multi-capacitated three-level supply chain design. Tofighi et al. (2016) consider capacity levels for central warehouses to select the facilities' storage capacity and establishing costs while optimizing a two-echelon humanitarian logistics network design problem by a two-stage scenario-based possibilisticstochastic programming approach.

In order to depict the financial leeway of a company, several models include budgets that are considered in isolation and must be managed so as to ensure that they are not exceeded. For example, Kouvelis and Rosenblatt (2002) develop a quantitative model for global supply chains and maximize the net present value (NPV) of cash flows, i.e., before-tax income, interest payments, depreciation expenses, loan payments and corporate income taxes. A discounting rate for each country and period is given. They distinguish between investments in distribution centers and subassembly plants. For financing, budget restrictions provide loans granted by the government. There are country-specific per-period interest rates on the loans. Moreover, cash expenditures in fixed assets that are not financed by external sources are included. Wilhelm et al. (2005) optimize the strategic design of an assembly system in an international business environment. The objective is to maximize the total after-tax profit, while facilities (including locations, technologies and capacities) are chosen, suppliers are selected, distribution centers are located, and transportation modes are planned. The model contains a budget limitation assuring that total fixed costs associated with prescribing facilities and transportation modes for specific end products do not exceed a given amount of money. Chakravarty (2005) propose a model for optimizing plant investment decisions. In this context, they decide on where and how much to invest, what quantities to produce, which products to absorb the investment overhead, what product amounts to export and how to price the products. The considered company maximizes its profits over the planning horizon. The author assumes that the company has a fixed sum available for investment in plants at the beginning of the planning horizon. Fleischmann et al. (2006) develop a strategic planning model to optimize the global production network of an automobile manufacturer. In particular, they consider the allocation of products to production sites over a 12-year planning horizon. The financial impact of physical investments on the cash flows is taken into account in an extended model with an objective function that minimizes the NPV of costs and 
investment expenditures. Due to the company's self-financing strategy, yearly investment budgets that are estimated for the whole planning horizon by the yearly cash flows are used.

Balancing of cash inflows and outflows in the long run is modeled by $\mathrm{Yi}$ and Reklaitis (2004), who consider average flow rates of cash flows into and out of a cash storage unit for this purpose. In this context, they integrate different cash flows (including temporary financial investments in marketable securities at a given interest rate) within an approach to determine the optimal design of a batch-storage network. Taking into account dividends to be paid in constant amounts to the stockholders, they ensure that the cash inventory is not exceeded. The source of the initial cash inventory as well as additional financing by bank loans is not considered. Moreover, their non-linear optimization model focuses on minimizing the annualized opportunity costs of capital investment for process/storage units and cash/material inventory minus the dividend to stockholders.

In contrast, Lavaja et al. (2006) use budgeting equations to balance the cash flows within the time periods of the planning horizon while modeling a network of processes including a plant location problem. In order to optimize their investment project spanning a planning horizon of 20 years, they apply the NPV method with an assumed discount factor for each time period. The NPV is constructed by the continuing proceeds of the project (that are equal to the cash effectively returned to the investor), the capital investments in expansions and the salvage value. The latter is set to a given percentage of the fixed capital investment. However, although the budgets of different time periods are related to each other, financing is limited to the maximum capital available and to the proceeds of the project (re-investments), but does not include instruments such as credits.

A wide variety of financial instruments, such as marketable securities, short-term financing and long-term debts, is taken into account within the model of GuillénGosálbez et al. (2006) that is proposed for simultaneous optimization of process operations and financial decisions in chemical supply chains. Their objective is to maximize the direct enhancement of shareholder's value in the firm that is equal to the increment in equity of the enterprise achieved at the end of the planning horizon. Their calculation of changes in equity is not only influenced by the cash flows balanced for each planning period, but also by current and fixed assets, liabilities, etc. that have a direct impact on the enhancement of the shareholder's value, but must not directly affect cash receipts and payments. In contrast to the latter approach that is not based on discounting rates, Laínez et al. (2007) maximize the corporate value by applying the discounted free cash flow (DFCF) method that uses the weighted average cost of capital (WACC) for discounting. Consequent to the fact that the DFCF method is appropriate to determining the total value of the firm to all investors, both equity holders and debt holders, the WACC rate considers the overall capital structure of the company including equity and debt. The free cash flows are the difference between the net operating profit after taxes and the increase in capital invested. As the authors' model strives for combining process operations and finances (taking strategic decisions of facility opening and capacity into account), a cash balance for each period is guaranteed by the use of financial instruments, i.e., marketable securities, short- and long-term credits. 
Longinidis and Georgiadis (2011) evaluate the financial performance of a company-wide multi-product, multi-period supply chain network with four echelons by maximizing the economic value added (EVA). With respect to a given dividend payout ratio during the time periods, they determine the associated design of the supply chain network including the numbers, locations and capacities of warehouses and distribution centers to be set up as well as transportation links to be established. The total invested capital is defined as the sum of shareholders' equity as well as short- and long-term liabilities. To avoid misinterpretations with respect to risk consideration within the WACC rate that is commonly used for calculating EVA, Hahn and Kuhn (2012a) assume an externally predefined hurdle rate to calculate the capital charge. Within their model, applicable to a make-to-stock supply chain in the consumer goods industry with single-stage production, they use an objective based on EVA, which allows for integrated performance and risk optimization. As a consequence, material flows and financial flows are optimized simultaneously within the time periods of the mid-term planning horizon. The cash position resulting from operations, open items management, financial management (shortterm investments and short-term borrowing at fixed interest rates) and exogenous cash flows (including dividend payouts) is balanced within each period. With regard to long-term planning, Hahn and Kuhn (2012b) refer to the market value added (MVA), which represents the multi-annual extension of the EVA concept, as it can be calculated as the sum of WACC-discounted EVA values up to the planning horizon. However, the aforementioned measures consider the profit that remains after accounting for the return expectations of the investors. Koberstein et al. (2013) propose an objective function of a weighted sum of the expected NPV of the profits and an additional conditional value at risk measure for their integrated strategic planning of global production networks. A company-specific interest rate (such as WACC) is used to compute the discounted cash flows. Their two-stage stochastic mixed-integer programming model, which takes uncertain exchange rates and product demands into account, includes strategic investment decisions as well as decisions on production and transportation quantities. The usage of financial instruments focuses on forward contacts and options. Sahling and Kayser (2016) use the combined maximization of the expected NPV and the conditional value of risk for strategic supply planning with vendor selection. The configuration of the threelayer supply network includes decisions on the selection of production facilities, the assignment of products to facilities, the selection of vendors for delivery of components and the assignment of retailers to production facilities. The considered cash flows include incoming and outgoing payments, e.g., for establishing, closing and running production facilities, installing tools at facilities, fulfilling demand at retailers, acquiring and transporting components as well as processing and transporting end products, which are discounted by a period-specific internal interest rate that is derived from WACC.

Our literature review above reveals that there is no approach that meets the requirements for our problem formulated in Sect. 1. In general, the integration of decisions on location and capacity planning, supplier and market selection as well as operations within supply chain networks is a well-researched area. However, with respect to discrete capacity planning modeled by capacity levels in literature, 
existing approaches do not consider the (monetary) investment or disinvestment consequences that arise from the change of capacity levels in subsequent time periods. Neither the aforementioned inter-temporal relationships between capacity levels nor their combination to alternatively selectable sequences (hereinafter referred to as alternatively selectable capacity profiles) have been analyzed so far. Several papers emphasize the need for an additional financial coordination. Approaches based on budgeting are unsuitable, as far as they do not allow for cash flow balancing between the time periods of the planning horizon. A few approaches implement the usage of instruments that allow for fixed rate debt financing during the limited engagement of an investor, but they neglect the impact of the company's overall debt capacity on interest payments. Furthermore, the aforementioned approaches do not provide objectives that are suitable for the maximization of the annual payouts to the investor. On the one hand, this applies to approaches neglecting the time value of money. On the other hand, this applies to the overwhelming majority of approaches based on discounting rates representing the company's overall cost of capital (such as WACC), i.e., a mixture of returns needed to compensate shareholders and creditors. Contrary to these entity approaches, the cash flows resulting from debt financing (interest payments including the resulting effects of the tax shield, changes in the overall debt) should be part of the cash flow calculation. Consequently, debt financing increases the value of firm, as interest payments to creditors reduce the taxable cash inflows from SC operations, and thus, the tax payments. The latter is considered within the flow-to-equity approach (Damodaran 2012). However, besides data-driven FTE approaches (e.g., Gardner et al. 2012, who are valuing a beverage company by analyzing the statement of cash flows and the income statement without any optimization), there is no model-driven FTE approach in the literature that allows for the coordination with supply chain planning so as to determine maximal payouts to the investor, to the best of our knowledge.

In summary, the main contributions of the modeling within this paper are as follows:

- For the lack of existing model-driven approaches that combine the flow-toequity method with supply chain planning in order to coordinate the return expectations of a financial investor after a business acquisition, we develop a suitable two-phase approach. The latter considers interdependencies between the investor's decisions during his engagement, and their consequences for the operations after his engagement. Thus, the calculation of the residual value (determining the selling price of the company) is part of the optimization.

- Duration-dependent interest rates (taking into account the specific time periods the transactions start and end) are used for debt financing. Moreover, these interest rates are a function of the debt limit of the company and the current total debt. As the latter is a result of the optimization, trade-offs between financing volume, interest payments, tax shield and FTE are considered within the resulting non-linear optimization model.

- Regarding capacity adjustments, we introduce alternatively selectable capacity profiles that allow for the assignment of capacity sequences to locations, starting 
with the beginning of the time period a location is opened or continued from the initial configuration. This enables capturing the monetary consequences of changes in capacity levels in subsequent time periods (cash outflows from investments, cash inflows from disinvestments) on the one hand, and reducing the model complexity (see Sect. 4 and results in Sect. 6) by focusing on the feasible/desired capacity sequences (see Sect. 3) on the other hand.

\section{Conceptual approach}

The supply chain controlled by the institutional investor includes several locations, which can be assigned to different supply chain stages. The number of supply chain stages is to be set according to the specific process interdependencies. Raw materials of different kinds can be obtained from external suppliers used in the procurement stage. A transformation process into intermediate and finished products is conducted in plant locations, which are located in $W$ subsequent production stages. Finished products are distributed by warehouse locations in $L$ subsequent distribution stages to meet the demand in the market stage. Production and distribution stages are separated to depict different activities (i.e., transformation and storage processes) and ingoing product states (i.e., raw materials, intermediate and finished products). The planning horizon determined by the investor's engagement is divided into time periods of 1 year each. Assuming an appropriate data aggregation, the simultaneous supply chain planning dominates successive approaches. However, as the simultaneous planning of all supply chain tasks is considered to be impracticable, short-term continuous-time models for production, distribution and scheduling (for example Steinrücke 2011, 2015) should be applied additionally after solving our proposed discrete-time model.

The adequate adjustment of production and storage capacities at the locations is enabled by capacity profile selection. Capacity profiles represent possible sequences of available maximum capacities (e.g., workforce, machines, shelves, etc. that determine the maximum quantity produced or stored at a location within one time period) in subsequent time periods of the planning horizon. These sequences start at the beginning of the planning horizon (if the location is a part of the initial configuration) or at the beginning of the time period the location is opened (if the location is not a part of the initial configuration) and are valid until the end of the planning horizon, if the location is not closed before. As a consequence of the assignment of a capacity profile to a location, the availability of capacity can vary according to feasible patterns. Ideal-typical forms of sequences are capacity extension (increasing available capacity), capacity stagnation (constant available capacity) and capacity downsizing (decreasing available capacity). Moreover, any other sequences can be modeled as a capacity profile. The benefits of capacity profiles in comparison to capacity levels (see Sect. 4) are as follows:

- The considered processes of production and storage are based on specific capacities (e.g., specialized machinery and skilled workers), which are production factors difficult to purchase or dispose of. Although potentially 
being optimal in case of leaving the capacity planning completely to the model, the repurchase of sold machines and the reinstatement of dismissed workers may be unrealistic with respect to given market conditions.

- Especially adjustments of personnel capacities may be restricted due to laws, contracts or social agreements. By the use of capacity profiles it is possible to model viable alternatives of capacity development that reflect the responsibility of the investor.

- With regard to the computational effort of optimization, the use of capacity profiles contributes to the reduction of complexity of the problem. By reducing the number of considered capacity sequences to the number of feasible/preferred alternatives, it is possible to reduce the computation times drastically (see Sect. 6). This provides an advantage for the practical implementation of our proposed model.

With regard to debt financing, the investor can make use of existing secure capital market finance alternatives with a duration from the beginning of time period $t$ until the end of time period $\vartheta(t \leq \vartheta)$ and duration-dependent credit rates to balance missing liquidity. It is assumed that the credit amount including the accumulated interests is redeemed in full. There are limits for the extent of single financing objects, and for the extent of financing objects starting simultaneously at the beginning of one time period. Moreover, the impact of the current total debt of the company and the existing debt limit on the credit rates offered to the company is taken into account. For the determination of a specific risk premium that increases the common base credit rate, a functional relationship (that is supposed to be known to or estimated by the network managers) is assumed. As a result, endogenous credit rates (that are depending on the optimal solution of the overall problem) are used for non-linear modeling.

Figure 1 depicts the modeled supply chain network structure.

As the investor strives for determining realizable annual cash outflows, the present value of the company's equity is maximized. In this context, supply chain network planning and financial planning are combined as follows:

\section{(A) Supply chain planning}

- Sales market selection: it must be decided which sales markets are supplied in which time periods with which products, and if demands are met in full or only at a specific percentage (partial deliveries).

- Facility location planning: within the process chain it must be decided which plant and warehouse locations in which supply chain stage are opened in which time period in addition to the initial configuration, and thus, are available for supply chain operations. Furthermore, it must be decided which of the available plant and warehouse locations of which supply chain stage are liquidated in which time period.

- Production and storage capacity planning: to adjust the locations' capacities, it must be decided to what extent capacities are made available in which existing or opened plant and warehouse locations of which supply chain stage in which time period. 


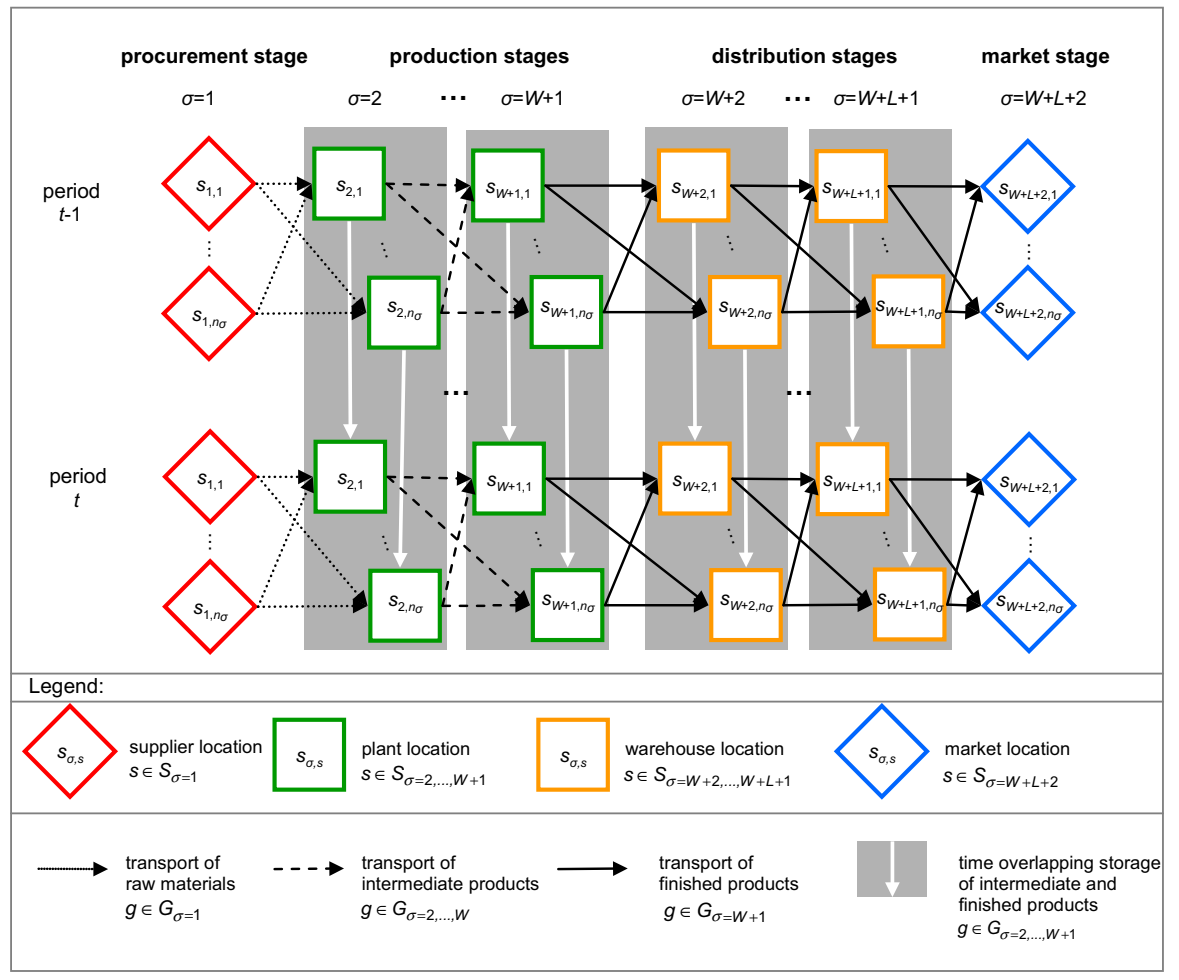

Fig. 1 Supply chain network structure

- External supplier selection: at the beginning of the process chain decisions concern which suppliers are selected in which time period for the raw material supply.

- Supply chain operations: decisions concern which products are manufactured in which plant location in which time period, which supplier delivers which raw materials in which time period, which locations receive what quantities from which locations in adjacent supply chain stages, and which plant and warehouse locations store what product amounts.

(B) Financial planning

With regard to financing, it must be decided which available credits (with different durations) are taken in which time period to what extent. The relevant credit rate that is offered to the company results from an assumed functional relationship.

The developed approach is exclusively based on cash flow series, which emerge from (i) supply chain planning and from (ii) financial planning.

(i) With regard to supply chain planning, there are cash flows resulting from configuration decisions, which are composed of cash outflows referring to 
location and capacity investments (e.g., opening of plant and warehouse locations and purchase of resources) and cash inflows resulting from location and capacity disinvestments. Additionally, there are cash outflows for the availability of plant and warehouse locations (e.g., rent, maintenance), cash outflows concerning procurement, production, storage and transport as well as cash outflows resulting from supplier business relations (e.g., receipt and inspection of raw materials) and market penetration (e.g., marketing and sales manager). The sum of all decisions creates the base for the supply chain operations. Cash inflows result from the commercialization at sales markets, but cannot be allocated to a single decision.

(ii) Cash flows emerging from financial planning are based on negotiated interest rates. Therefore, cash inflows are directly relatable to corresponding cash outflows, in contrast to the aforementioned supply chain planning. In particular, there are cash inflows resulting from money borrowing at the capital market. According to solvency, a specific amount can be borrowed and leads to one cash outflow including the full redemption plus interests at maturity (final date redemption). Limited financing objects are considered in the following.

All annual cash flows emerging from supply chain planning and financial planning are merged taking the payouts to the investor into account. The financial balance guarantees that the sum of cash inflows is not exceeded by the sum of cash outflows.

Notation:

Indices

$\sigma \quad$ SC stage index, $\sigma \in \Gamma:=\{1, \ldots, W+L+2\}$ (see Fig. 1) (note: $\sigma=1$ for procurement stage; $\sigma=2, \ldots, W+1$ for production stages; $\sigma=W+2, \ldots, W+L+1$ for distribution stages; $\sigma=W+L+2$ for market stage);

$s, q$ location indices, $s, q \in S_{\sigma}$;

$k \quad$ capacity profile index, $k \in K_{\sigma \tau}$;

$g, f$ product indices, $g, f \in G_{\sigma}$;

$t, \vartheta$ time period indices, $t, \vartheta \in T:=\left\{1, \ldots, t_{E}, t_{E}+1\right\}$; (note: $t_{E}$ represents the last time period of the investor's engagement; $t_{E}+1$ represents the first time period after the investor's engagement)

$\tau$ time period index representing a location's opening, $\tau \in T *:=\left\{0, \ldots, t_{E}\right\}$ (note: $\tau=0$ represents the initial configuration);

\section{Parameters}

$\gamma_{t} \quad$ technical parameter, $\gamma_{t}=\left\{\begin{array}{lc}1, & t=1, \ldots, t_{E} \\ 0, & t=t_{E}+1\end{array}\right.$

$\kappa_{f g}^{\sigma} \quad$ units of raw material or intermediate product $f$ required for the production of one unit of product $g$ in plant locations of the SC stage $\sigma$;

$\lambda_{g}^{\sigma} \quad$ units of storage capacity used by one unit of product $g$ in plant/warehouse locations of the SC stage $\sigma$; 
$\rho_{g}^{\sigma} \quad$ units of production capacity used by one unit of product $g$ in plant locations of the SC stage $\sigma$;

$v_{g}^{\sigma, \sigma+1} \quad$ units of transportation capacity used by one unit of product $g$ between locations of the adjacent SC stages $\sigma$ and $\sigma+1$;

$C A_{s t}^{\sigma} \quad$ cash outflow resulting from the availability of location $s$ of SC stage $\sigma$ during time period $t$;

$C F_{q s t}^{\sigma, \sigma+1}$ cash outflow resulting from transportation from location $q$ to location $s$ of the adjacent SC stages $\sigma$ and $\sigma+1$ during time period $t$;

$C K_{k s t}^{\sigma \tau} \quad$ cash outflow resulting from the assignment of capacity profile $k$ to the plant/warehouse location $s$ (opened at the beginning of time period $\tau$ ) of SC stage $\sigma$ at the beginning of time period $t$ (note: $C K_{k s t}^{\sigma \tau}<0$ represents cash inflow);

$C L_{s t}^{\sigma} \quad$ cash inflow resulting from the liquidation of a plant/warehouse location $s$ of SC stage $\sigma$ at the beginning of time period $t$;

$\mathrm{CO}_{s t}^{\sigma} \quad$ cash outflow resulting from the opening of a plant/warehouse location $s$ of SC stage $\sigma$ at the beginning of time period $t$;

$\mathrm{CP}_{\mathrm{gst}}^{\sigma} \quad$ cash outflow resulting from the production of one unit of product $g$ at the plant location $s$ of SC stage $\sigma$ during time period $t$;

$C R_{g s t} \quad$ cash outflow resulting from the procurement of one unit of raw material $g$ from supplier location $s$ during time period $t$;

$C S_{g s t}^{\sigma} \quad$ cash outflow resulting from the storage of one unit of product $g$ at the plant/warehouse location $s$ of SC stage $\sigma$ in time period $t$;

$C V_{\text {gqst }}^{\sigma, \sigma+1}$ cash outflow resulting from the transportation of one unit of product $g$ from location $q$ to location $s$ of the adjacent SC stages $\sigma$ and $\sigma+1$ during time period $t$;

$D_{g s t} \quad$ demand of the final product $g$ at the market location $s$ in time period $t$;

$\mathrm{DEB}_{0} \quad$ initial debt;

$\mathrm{DEB}^{\mathrm{max}}$ maximum debt;

$D N_{t} \quad$ depreciations and other non-cash expenses during time period $t$;

$F_{\vartheta t}^{\mathrm{obj}} \quad$ credit line of a single financing object with a duration from the beginning of time period $\vartheta$ until the end of time period $t(\vartheta \leq t)$;

$F_{t}^{\text {per }} \quad$ credit line of all financing objects used together at the beginning of time period $t$;

$i_{\vartheta t}^{\mathrm{BASE}}$ base interest rate for a financing object with a duration from the beginning of time period $\vartheta$ until the end of time period $t(\vartheta \leq t)$;

$L \quad$ number of distribution stages within the entire supply chain;

$P C_{s t} \quad$ maximum production capacity at supplier location $s$ during time period $t$; $P C_{s k t}^{\sigma \tau} \quad$ maximum production capacity at plant location $s$ (which has been opened within SC stage $\sigma$ at the beginning of time period $\tau$ with the capacity profile $k$ ) during time period $t$;

$r^{E Q} \quad$ cost of equity to be calculated by the capital asset pricing model (see Sect. 5);

$S I_{g s}^{\sigma} \quad$ units of product $g$ initially stored in plant/warehouse location $s$ of SC stage $\sigma$ at the beginning of the investor's engagement; 
$S C_{s t}^{\sigma} \quad$ maximum storage capacity at plant location $s$ of SC stage $\sigma$ during time period $t$;

$S C_{s k t}^{\sigma \tau} \quad$ maximum storage capacity at warehouse location $s$ (which has been opened within SC stage $\sigma$ at the beginning of time period $\tau$ with the capacity profile $k$ ) during time period $t$;

$S P_{g s t} \quad$ sales price of one unit of final product $g$ at market location $s$ in time period $t$;

$T C_{q s t}^{\sigma, \sigma+1}$ maximum transportation capacity for transports from location $q$ to location $s$ of the adjacent SC stages $\sigma$ and $\sigma+1$ during time period $t$;

$T X \quad$ average tax rate;

$V S_{g s}^{\sigma} \quad$ value of one unit of product $g$ stored in plant/warehouse location $s$ of SC stage $\sigma$ at the end of the investor's engagement (value of storage carryover);

$W \quad$ number of production stages within the entire supply chain;

$y_{s 0}^{\sigma} \quad$ equals 1 if plant/warehouse location $s$ of SC stage $\sigma$ is part of the initial configuration, and 0 otherwise (binary parameter);

Decision variables

$c_{s t}^{\sigma} \quad$ equals 1 if a plant/warehouse location $s$ of SC stage $\sigma$ is liquidated at the beginning of time period $t$, and 0 otherwise;

$\operatorname{con}_{t} \quad$ cash inflow resulting from adjustments of the SC configuration at the beginning of time period $t$ (note: $\operatorname{con}_{t}<0$ represents cash outflow);

$\mathrm{DEB}_{t} \quad$ total debt at the end of time period $t$;

$f_{t \vartheta} \quad$ cash inflow resulting from the usage of a financing object with a duration from the beginning of time period $t$ until the end of time period $\vartheta(t \leq \vartheta)$;

$\mathrm{FTE}_{t} \quad$ flow to equity at the end of time period $t$, which is equal to the cash outflow to the investor during his engagement (note: $\mathrm{FTE}_{t}<0$ represents the cash inflow from the investor; $\mathrm{FTE}_{0}$ represents the cash flow at the beginning of the investor's engagement, i.e., at the beginning of time period $t=1$ );

$i_{\vartheta t}^{F O}\left(\mathrm{DEB}_{\vartheta}\right)$ interest rate of a financing object, cumulated over the duration from the beginning of time period $\vartheta$ until the end of time period $t(\vartheta \leq t)$, as a function of $\operatorname{DEB}_{\vartheta}$ (see Sect. 5);

$o_{s t}^{\sigma} \quad$ equals 1 if a plant/warehouse location $s$ of SC stage $\sigma$ is opened at the beginning of time period $t$, and 0 otherwise;

ope $_{t} \quad$ cash inflow resulting from SC operations during time period $t$ (note: ope $_{t}<0$ represents cash outflow);

$p r_{g s t}^{\sigma} \quad$ units of product $g$ produced in plant location $s$ of SC stage $\sigma$ during time period $t$;

$R V_{t_{E}} \quad$ residual value of expected FTE at the end of the investor's engagement;

$s t_{g s t}^{\sigma} \quad$ units of product $g$ stored in plant/warehouse location $s$ of SC stage $\sigma$ at the beginning of time period $t$; 
$t_{q s t}^{\sigma, \sigma+1} \quad$ equals 1 if transportation from location $q$ to location $s$ of the adjacent SC stages $\sigma$ and $\sigma+1$ is conducted during time period $t$, and 0 otherwise;

VEQ present value of equity;

$x_{g q s t}^{\sigma, \sigma+1} \quad$ units of product $g$ transported from location $q$ to location $s$ of the

$y_{s t}^{\sigma} \quad$ equals 1 if supplier or market location $s$ of SC stage $\sigma$ is selected in adjacent SC stages $\sigma$ and $\sigma+1$ during time period $t$; time period $t$, and 0 otherwise;

$y_{s k t}^{\sigma \tau} \quad$ equals 1 if a plant/warehouse location $s$ (which has been opened within SC stage $\sigma$ at the beginning of time period $\tau$ with the capacity profile $k$ ) is available in time period $t$, and 0 otherwise.

The structure of the conceptual approach to coordinate supply chain network planning and financial planning is depicted in Fig. 2.

All relevant decisions are subordinated to the institutional investor's aims, in particular the withdrawal of realizable payouts while respecting the maximization of the present value of equity (Sect. 3.1). However, these withdrawals penalize the business liquidity. Taking this into account, the period cash inflows and outflows are balanced in the solvency constraints (Sect. 3.2) in order to ensure the continuation of the company. As mentioned before, cash flows can arise from SC configuration

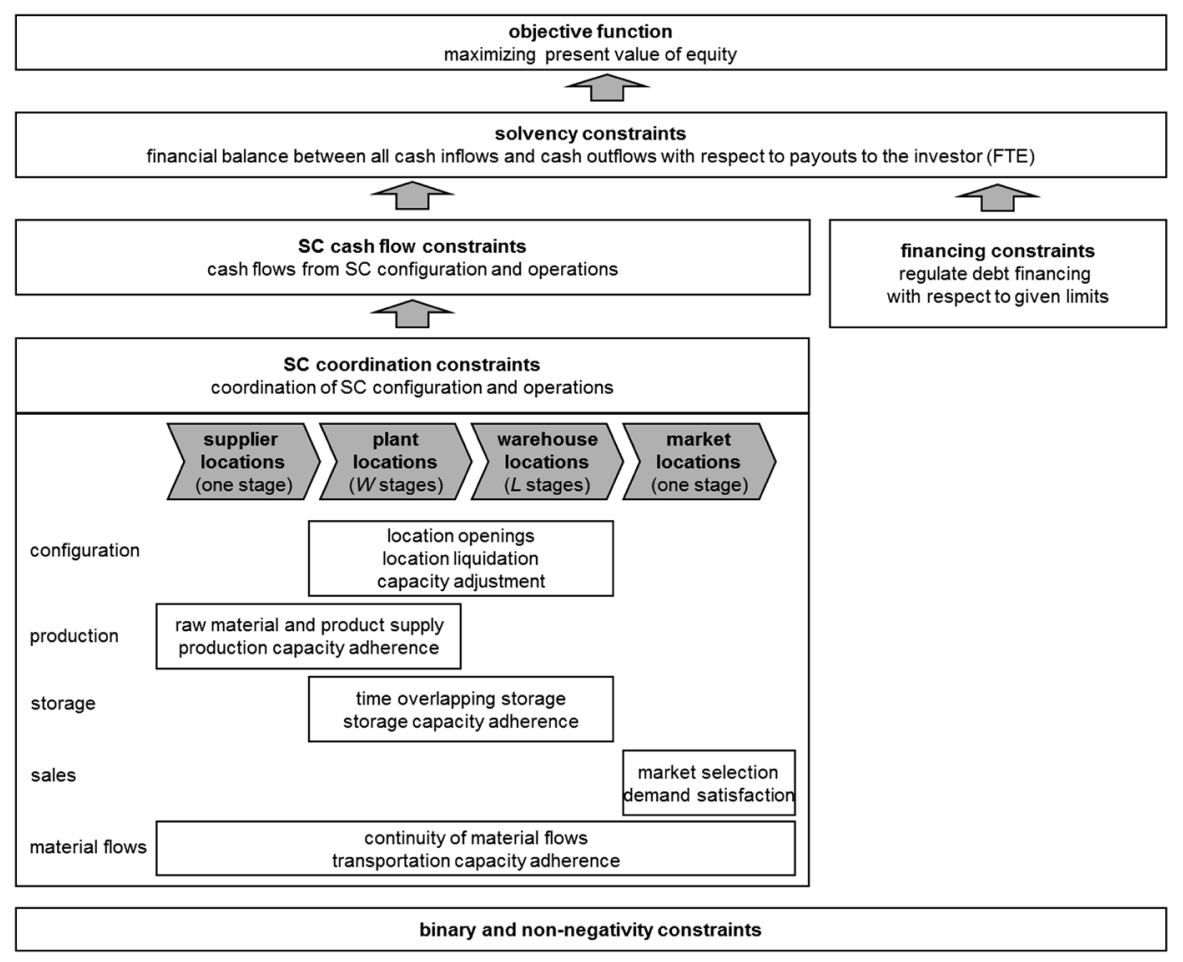

Fig. 2 Structure of the decision model 
and operations. Both of them are merged within the SC cash flow constraints (Sect. 3.4). As the latter cash flows are restricted by the status of the current network (availability of external suppliers, producers, distributors and sales markets), we consider SC coordination constraints (Sect. 3.5) that allow for adequate capacity usages. Additionally, cash flows which result from usages of available financing instruments (that depend on the market settings and credibility, and thus, are not available without limitations) must be taken into account within the financing constraints (Sect. 3.3).

\subsection{Objective function}

$$
\begin{gathered}
\max \mathrm{VEQ}=\left(\sum_{t=0}^{t_{E}} \frac{\mathrm{FTE}_{t}}{\left(1+r^{E Q}\right)^{t}}\right)+\frac{R V_{t_{E}}}{\left(1+r^{E Q}\right)^{t_{E}}} \\
R V_{t_{E}}=\frac{\mathrm{FTE}_{t_{E}+1}}{r^{E Q}}+\sum_{\sigma=2}^{W+1} \sum_{g \in G_{\sigma}} \sum_{s \in S_{\sigma}} V S_{g s}^{\sigma} \cdot s t_{g s, t_{E}+1}^{\sigma}+\sum_{\sigma=W+2}^{W+L+1} \sum_{g \in G_{W+1}} \sum_{s \in S_{\sigma}} V S_{g s}^{\sigma} \cdot s t_{g s, t_{E}+1}^{\sigma}
\end{gathered}
$$

The objective (1), which is based on the two-stage free cash flow to equity model of Damodaran (2012), is to maximize the present value of equity while determining the cash flows to (or even from) the institutional investor (i.e., the flows to equity) in each time period of his engagement. Furthermore, the residual value of equity (after the institutional investor terminates his engagement) is taken into account [see (2)]. For its determination, we assume that FTE of the first time period after the investor's engagement can be reproduced in each of the following time periods (see Fig. 3). The overall value of storage carryover (i.e., storage quantities of intermediate products and finished products that remain at the company's locations after the investor's engagement) needs to be added. As the investor's earnings have to be calculated for each time period, a suitable discounting factor must be determined for respecting the time value of money and the specific business risk. In the financial literature, the capital asset pricing model (CAPM) introduced by Sharpe (1964) is mainly used for the determination of the cost of equity capital of a levered company (Schmidlin 2014). The latter discounting rate depends on the riskfree rate of return, the expected market rate of return and the company-specific risk coefficient (beta factor) (see Sect. 5).

$\begin{gathered}\text { period before } \\ \text { the investor's } \\ \text { engagement }\end{gathered}$
configuration

Fig. 3 Time representation 


\subsection{Solvency constraints}

The solvency constraints ensure the continuation of the company while realizing the FTE payouts. For this purpose, the FTE are coordinated with all relevant cash flows of the company that can be assigned to the time periods of the investor's engagement.

At the beginning of the investor's engagement [beginning of time period $t=1$, see (3)] it is possible to vary existing structures of the initial configuration (by location and capacity investments as well as disinvestments). For this purpose, additional funds of the investor $\left(\mathrm{FTE}_{0}<0\right)$ and/or credits can be used. These initial decisions provide the basis for supply chain operations during this period leading to surpluses.

$$
\mathrm{con}_{1}+\sum_{\vartheta=1}^{t_{E}} f_{1 \vartheta} \geq \mathrm{FTE}_{0} .
$$

At the beginning of all the following periods of the investor's engagement [beginning of time periods $t=2, \ldots, t_{E}$, see (4)], the cash flows from operations generated during the previous time period are available. According to the tax shield, the latter are adjusted for the interest expenses that become relevant at this point in time. Although depreciation and other non-cash expenses are not relevant for the calculation of FTE in general as they are accounting expenses, their tax effects can be considered by a correction term. Cash flows are further influenced by physical investment cash flows resulting from location and capacity decisions (summed up to net investments in locations and capacity), as well as cash inflows (credit amounts resulting from credits that are starting at the beginning of the current period) and cash outflows (repayment amounts resulting from credits that are ending at the end of the previous period) from financial transactions. In accordance with existing calculation schemes (e.g., Ernst and Häcker 2012 and Mandl and Rabel 1997, see also Table 1), the free cash flow to equity remains as realizable cash outflow to the investor.

$$
\begin{aligned}
& \underbrace{\left[\text { ope }_{t-1}-\sum_{\vartheta=1}^{t-1} i_{\vartheta, t-1}^{F O}\left(\mathrm{DEB}_{\vartheta}\right) \cdot f_{\vartheta, t-1}\right]}_{\begin{array}{c}
\text { operating cash flow } \\
\text { minus interest expense }
\end{array}} \cdot(1-\mathrm{TX}) \\
& +\underbrace{D N_{t-1} \cdot \mathrm{TX}}_{\text {corretion term }}+\underbrace{\operatorname{con}_{t}}_{\text {net investment }}+\underbrace{\sum_{\vartheta=t}^{t_{E}} f_{t \vartheta}-\sum_{\vartheta=1}^{t-1} f_{\vartheta, t-1}}_{\text {net borrowing }} \geq \mathrm{FTE}_{t-1} ;
\end{aligned}
$$

At the end of the engagement [end of time period $t_{E}$, see (5)], the last cash outflow to the investor is calculated. FTE is composed by the surpluses realized during the last period $t_{E}$ and the cash outflows from ending financial transactions. 
Furthermore, final decisions on the supply chain structure (influencing the residual value) are possible.

$$
\begin{aligned}
& {\left[\mathrm{ope}_{t_{E}}-\sum_{\vartheta=1}^{t_{E}} i_{\vartheta t_{E}}^{F O}\left(\mathrm{DEB}_{\vartheta}\right) \cdot f_{\vartheta t_{E}}\right] \cdot(1-\mathrm{TX})+D N_{t_{E}} \cdot \mathrm{TX}+\mathrm{con}_{t_{E}+1}} \\
& -\sum_{\vartheta=1}^{t_{E}} f_{\vartheta t_{E}} \geq \mathrm{FTE}_{t_{E}}
\end{aligned}
$$

After the engagement of the investor [see (6)] equal FTE are assumed to be generated at the end of each following period. Due to the lack of further information about the decisions of upcoming holders, these FTE are based upon operations that can be generated in the network structure that is available at the end of the investor's engagement.

$$
\text { ope }_{t_{E}+1} \cdot(1-\mathrm{TX}) \geq \mathrm{FTE}_{t_{E}+1} \text {. }
$$

\subsection{Financing constraints}

As the interest rates offered to the investor are dependent on current total debt of the acquired supply chain, the latter must be determined at the beginning of each time period.

At the beginning of the investor's engagement [beginning of time period $t=1$, see (7)], the initial debt (being valid at the time point of acquisition) is increased by credit amounts taken for changes of the initial network configuration. With regard to the beginning of all further periods of the investor's engagement [beginning of time periods $t=2, \ldots, t_{E}$, see (8)], the current total debt results from the previous total debt adjusted for relevant credit amounts and repayment amounts [cf. (4)]. Due to existing debt limits, constraints (9) are valid.

$$
\begin{gathered}
\mathrm{DEB}_{0}+\sum_{\vartheta=1}^{t_{E}} f_{1 \vartheta}=\mathrm{DEB}_{1} \\
\mathrm{DEB}_{t-1}+\sum_{\vartheta=t}^{t_{E}} f_{t \vartheta}-\sum_{\vartheta=1}^{t-1} f_{\vartheta, t-1}=\mathrm{DEB}_{t} ; \quad \forall t=2, \ldots, t_{E} \\
\mathrm{DEB}_{t} \leq \mathrm{DEB}^{\text {max }} ; \quad \forall t=1, \ldots, t_{E} .
\end{gathered}
$$

Besides the aforementioned restrictions on the total debt, constraints (10) limit the extent of single financing objects and constraints (11) limit the extent of simultaneously starting financing objects at the beginning of time period $t$.

$$
\begin{gathered}
f_{t \vartheta} \leq F_{t \vartheta}^{\mathrm{obj}} ; \quad \forall t=1, \ldots, t_{E} ; \quad \vartheta=1, \ldots, t_{E} ; \quad \vartheta \geq t \\
\sum_{\vartheta=t}^{t_{E}} f_{t \vartheta} \leq F_{t}^{\mathrm{per}} ; \quad \forall t=1, \ldots, t_{E} .
\end{gathered}
$$




\subsection{Supply chain cash flow constraints}

The FTE are influenced by cash flows according to the configuration resulting from decisions at the beginning of a time period and cash flows according to supply chain operations resulting from decisions during a time period.

$$
\begin{gathered}
\operatorname{con}_{t}=\underbrace{-\sum_{\sigma=2}^{W+L+1} \sum_{s \in S_{\sigma}} C O_{s t}^{\sigma} \cdot o_{s t}^{\sigma}}_{\text {location opening }}+\underbrace{\sum_{\sigma=2}^{W+L+1} \sum_{s \in S_{\sigma}} C L_{s t}^{\sigma} \cdot c_{s t}^{\sigma}}_{\text {location liquidation }} \\
\underbrace{-\sum_{\sigma=2}^{W+L+1} \sum_{\tau=0}^{t} \sum_{k \in K_{\sigma \tau}} \sum_{s \in S_{\sigma}} C K_{k s t}^{\sigma \tau} \cdot y_{s k t}^{\sigma \tau}}_{\text {location capacity adjustment }} ; \quad \forall t=1, \ldots, t_{E}+1 .
\end{gathered}
$$

Cash flows according to the configuration [see (12)] contain investment cash outflows resulting from location openings and disinvestment cash inflows resulting from location closings. As such closings are only possible for locations that are part of the initial configuration [cf. (22)], liquidation cash inflow parameters that decrease with increasing time periods of closing can be used to reflect a time-based degradation. Furthermore, there are cash flows resulting from capacity adjustments according to the selected capacity profile.

$$
\begin{aligned}
& \text { ope }_{t}=\underbrace{\sum_{g \in G_{W+1}} \sum_{s \in S_{W+L+2}} S P_{g s t} \cdot \sum_{q \in S_{W+L+1}} x_{g q s t}^{W+L+1, W+L+2}}_{\text {sales }}-\underbrace{\sum_{g \in G_{1}} \sum_{s \in S_{1}} C R_{g s t} \cdot \sum_{q \in S_{2}} x_{g s q t}^{1,2}}_{\text {procurement }} \underbrace{-\sum_{\sigma=2}^{W+1} \sum_{g \in G_{\sigma}} \sum_{s \in S_{\sigma}} C P_{g s t}^{\sigma} \cdot p r_{g s t}^{\sigma}}_{\text {production }} \\
& -\sum_{\sigma=1}^{W} \sum_{g \in G_{\sigma}} \sum_{q \in S_{\sigma}} \sum_{s \in S_{\sigma+1}} C V_{g q s t}^{\sigma, \sigma+1} \cdot x_{g q s t}^{\sigma, \sigma+1}-\sum_{\sigma=W+1}^{W+L+1} \sum_{g \in G_{W+1}} \sum_{q \in S_{\sigma}} \sum_{s \in S_{\sigma+1}} C V_{g q s t}^{\sigma, \sigma+1} \cdot x_{g q s t}^{\sigma, \sigma+1} \\
& \underbrace{-\sum_{\sigma=1}^{W+L+1} \sum_{q \in S_{\sigma}} \sum_{s \in S_{\sigma+1}} C F_{q s t}^{\sigma, \sigma+1} \cdot t_{q s t}^{\sigma, \sigma+1}}_{\text {transportation }} \\
& \underbrace{-\sum_{s \in S_{1}} C A_{s t}^{1} \cdot y_{s t}^{1}-\sum_{\sigma=2}^{W+L+1} \sum_{\tau=0}^{t} \sum_{s \in S_{\sigma}} \sum_{k \in K_{\sigma \tau}} C A_{s t}^{\sigma} \cdot y_{s k t}^{\sigma \tau}-\sum_{s \in S_{W+L+2}} C A_{s t}^{W+L+2} \cdot y_{s t}^{W+L+2}}_{\text {availability }} \\
& \underbrace{-\gamma_{t} \cdot\left(\sum_{\sigma=2}^{W+1} \sum_{g \in G_{\sigma}} \sum_{s \in S_{\sigma}} C S_{g s t}^{\sigma} \cdot s t_{g s t}^{\sigma}+\sum_{\sigma=W+2}^{W+L+1} \sum_{g \in G_{W+1}} \sum_{s \in S_{\sigma}} C S_{g s t}^{\sigma} \cdot s t_{g s t}^{\sigma}\right)}_{\text {storage }} ; \quad \forall t=1, \ldots, t_{E}+1
\end{aligned}
$$

Cash flows according to supply chain operations: the resulting SC operations surpluses comprise accumulated components from Eq. (13). Cash inflows originate from sales. Procurement, production and transportation cash outflows are related to the relevant quantities. When company-owned locations (i.e., plants and warehouses) are operating on the one hand, or when external suppliers or markets are 
selected on the other hand, periodic availability cash outflows influence the surpluses. Time overlapping product storages at plant and warehouse locations lead to storage cash outflows. By the use of a technical parameter, the terms for the calculation of storage costs are omitted in time period $t_{E}+1$, as the value of storage carryover at the end of the planning horizon is already considered within the residual value [cf. (2)].

\subsection{Supply chain coordination constraints}

\subsubsection{Configuration}

The SC design consists of company-owned plant and warehouse locations. The continued operation of existing locations (that are part of the initial configuration at the time of acquisition) and the opening of new locations are possible in addition to location closings. The locations' capacities can be adjusted by selection of a capacity profile.

$$
c_{s t}^{\sigma}+\sum_{\tau=0}^{t} \sum_{k \in K_{\sigma \tau}} y_{s k t}^{\sigma \tau} \leq 1 ; \quad \forall s \in S_{\sigma}, \quad \sigma=2, \ldots, W+L+1, \quad t=1, \ldots, t_{E}+1
$$

Location status: the status of plant or warehouse locations is defined by (14) in each time period of the planning horizon. At most one capacity profile can be assigned to an available location. If the location is liquidated, then it is not available.

$$
\begin{gathered}
o_{s t}^{\sigma} \geq \sum_{\tau=0}^{t} \sum_{k \in K_{\sigma \tau}} y_{s k t}^{\sigma \tau}-\sum_{\tau=0}^{t-1} \sum_{k \in K_{\sigma \tau}} y_{s k, t-1}^{\sigma \tau} ; \quad \forall s \in S_{\sigma}, \quad \sigma=2, \ldots, W+L+1, \\
t=2, \ldots, t_{E}+1 \\
o_{s 1}^{\sigma} \geq \sum_{\tau=0}^{1} \sum_{k \in K_{\sigma \tau}} y_{s k 1}^{\sigma \tau}-y_{s 0}^{\sigma} ; \quad \forall s \in S_{\sigma}, \quad \sigma=2, \ldots, W+L+1
\end{gathered}
$$

Location opening: an opening occurs according to (15), when a location is available in a specific time period and not available in the previous time period (regardless of the selected capacity profile). Constraints (16) analogously concern the possible extension of the initial configuration at the beginning of period $t=1$.

$$
\begin{gathered}
c_{s t}^{\sigma} \leq \sum_{\tau=0}^{t-1} \sum_{k \in K_{\sigma \tau}} y_{s k, t-1}^{\sigma \tau} ; \quad \forall s \in S_{\sigma}, \quad \sigma=2, \ldots, W+L+1, \quad t=2, \ldots, t_{E}+1 \\
c_{s 1}^{\sigma} \leq y_{s 0}^{\sigma} ; \quad \forall s \in S_{\sigma}, \quad \sigma=2, \ldots, W+L+1
\end{gathered}
$$

Location liquidation: according to (17), liquidation requires that a location was available in the previous time period. Constraints (18) analogously concern liquidations of locations at the beginning of time period $t=1$, which were part of 
the initial configuration. In this context, constraints (14) guarantee that the locations' availability is excluded after liquidation.

$$
\begin{gathered}
y_{s k, t-1}^{\sigma \tau} \leq c_{s t}^{\sigma}+y_{s k t}^{\sigma \tau} ; \quad \forall s \in S_{\sigma}, \quad k \in K_{\sigma \tau}, \quad \sigma=2, \ldots, W+L+1, \\
\quad \tau=0, \ldots, t-1, \quad t=2, \ldots, t_{E}+1 \\
o_{s \tau}^{\sigma} \leq \sum_{k \in K_{\sigma \tau}} y_{s k \tau}^{\sigma \tau} ; \quad \forall s \in S_{\sigma}, \quad \sigma=2, \ldots, W+L+1, \quad \tau=1, \ldots, t_{E}+1 \\
y_{s 0}^{\sigma} \leq c_{s 1}^{\sigma}+\sum_{k \in K_{\sigma 0}} y_{s k 1}^{\sigma 0} ; \quad \forall s \in S_{\sigma}, \quad \sigma=2, \ldots, W+L+1
\end{gathered}
$$

Assignment of capacity profiles: according to (19), the capacity profile assigned to a location is valid until the end of the investor's engagement and beyond, as long as the location is not closed before. A capacity profile is assigned at location opening by (20) and to locations of the initial configuration by (21).

$$
\sum_{t=1}^{t_{E}+1} o_{s t}^{\sigma}+c_{s t}^{\sigma} \leq 1 ; \quad \forall s \in S_{\sigma}, \quad \sigma=2, \ldots, W+L+1
$$

Unrepeatable location opening and liquidation: constraints (22) ensure that locations opened during the investor's engagement cannot be liquidated and vice versa. Usually this relationship between such decisions endogenously results from significant differences between opening and liquidation cash flows, but it is manifested for the given planning horizon by the aforementioned constraints for reasons of planning continuity and reliability.

\subsubsection{Production}

$$
\begin{aligned}
& \sum_{q \in S_{\sigma-1}} x_{f q s t}^{\sigma-1, \sigma}=\sum_{g \in G_{\sigma}} \kappa_{f g}^{\sigma} \cdot p r_{g s t}^{\sigma} ; \quad \forall f \in G_{\sigma-1}, \quad s \in S_{\sigma}, \quad \sigma=2, \ldots, W+1, \\
& \quad t=1, \ldots, t_{E}+1
\end{aligned}
$$

Supply of raw materials and intermediates: constraints (23) ensure that the required quantities of raw materials and/or intermediate products (resulting from given production coefficients) are supplied to the plant locations to start manufacturing.

$$
\begin{gathered}
\sum_{g \in G_{1}} \rho_{g}^{1} \cdot \sum_{q \in S_{2}} x_{g s q t}^{1,2} \leq P C_{s t} \cdot y_{s t}^{1} ; \quad \forall s \in S_{1}, \quad t=1, \ldots, t_{E}+1 \\
\sum_{g \in G_{\sigma}} \rho_{g}^{\sigma} \cdot p r_{g s t}^{\sigma} \leq \sum_{\tau=0}^{t} \sum_{k \in K_{\sigma \tau}} P C_{s k t}^{\sigma \tau} \cdot y_{s k t}^{\sigma \tau} ; \quad \forall s \in S_{\sigma}, \quad \sigma=2, \ldots, W+1, \\
t=1, \ldots, t_{E}+1
\end{gathered}
$$

Adherence to production capacities: constraints (24) prohibit that the maximum capacities of supplier locations are violated. Likewise, (25) prevent that the maximum production capacities of plant locations, determined by the selected capacity profiles, are exceeded. 
3.5.3 Storage

$$
\begin{gathered}
s t_{g s t}^{\sigma}=s t_{g s, t-1}^{\sigma}+p r_{g s, t-1}^{\sigma}-\sum_{q \in S_{\sigma+1}} x_{g s q, t-1}^{\sigma, \sigma+1} ; \quad \forall g \in G_{\sigma}, \quad s \in S_{\sigma}, \\
\sigma=2, \ldots, W+1, \quad t=2, \ldots, t_{E}+1 \\
s t_{g s t}^{\sigma}=s t_{g s, t-1}^{\sigma}+\sum_{q \in S_{\sigma-1}} x_{g q s, t-1}^{\sigma-1, \sigma}-\sum_{q \in S_{\sigma+1}} x_{g s q, t-1}^{\sigma, \sigma+1} ; \quad \forall g \in G_{W+1}, \quad s \in S_{\sigma}, \\
\sigma=W+2, \ldots, W+L+1, \quad t=2, \ldots, t_{E}+1 \\
s t_{g s 1}^{\sigma}=S I_{g s}^{\sigma} ; \quad \forall g \in G_{\sigma}, \quad s \in S_{\sigma}, \quad \sigma=2, \ldots, W+1 \\
s t_{g s 1}^{\sigma}=S I_{g s}^{\sigma} ; \quad \forall g \in G_{W+1}, \quad s \in S_{\sigma}, \quad \sigma=W+2, \ldots, W+L+1
\end{gathered}
$$

Time overlapping storage: according to (26), the storage quantity of a plant location at the beginning of a specific time period results from the location's production, distribution and storage quantities during the previous time period. Considering the time overlapping storage in warehouse locations in (27), the production quantities must be replaced by the ingoing quantities from the plant locations. Initial storages at the plant and warehouse locations are defined by (28) and (29), respectively. Final storages resulting from (26) and (27) at the beginning of time period $t_{E}+1$ (which represents the end of the investor's engagement) cannot be considered for the planning of operations in time period $t_{E}+1$ (as the latter is assumed to be infinitely repeatable), but they are considered for the residual value in (2).

$$
\begin{aligned}
& \sum_{g \in G_{\sigma}} \lambda_{g}^{\sigma} \cdot\left(\gamma_{t} \cdot s t_{g s t}^{\sigma}+p r_{g s t}^{\sigma}\right) \leq S C_{s t}^{\sigma} \cdot \sum_{\tau=0}^{t} \sum_{k \in K_{\sigma \tau}} y_{s k t}^{\sigma \tau} ; \quad \forall s \in S_{\sigma}, \quad \sigma=2, \ldots, W+1, \\
& t=1, \ldots, t_{E}+1
\end{aligned}
$$

$$
\begin{aligned}
& \sum_{g \in G_{W+1}} \lambda_{g}^{\sigma} \cdot\left(\gamma_{t} \cdot s t_{g s t}^{\sigma}+\sum_{q \in S_{\sigma-1}} x_{g q s t}^{\sigma-1, \sigma}\right) \leq \sum_{\tau=0}^{t} \sum_{k \in K_{\sigma \tau}} S C_{s k t}^{\sigma \tau} \cdot y_{s k t}^{\sigma \tau} ; \quad \forall s \in S_{\sigma}, \\
& \sigma=W+2, \ldots, W+L+1, \quad t=1, \ldots, t_{E}+1
\end{aligned}
$$

Adherence to storage capacities: with regard to the plant locations, constraints (30) ensure that existing storage quantities (resulting from production of previous time periods) increased by new production quantities do not exceed the available maximum storage capacity. The latter is determined by the selected capacity profile, if warehouse locations are considered in (31). In the latter case, ingoing quantities are used instead of production quantities. Note that storage quantities are omitted for time period $t_{E}+1$ by using the technical parameter.

\subsubsection{Sales}

$$
\begin{aligned}
& \sum_{q \in S_{W+L+1}} x_{g q s t}^{W+L+1, W+L+2} \leq D_{g s t} \cdot y_{s t}^{W+L+2} ; \forall g \in G_{W+1}, \quad s \in S_{W+L+2}, \\
& \quad t=1, \ldots, t_{E}+1
\end{aligned}
$$


Sales market selection and demand satisfaction: if markets are selected, their demand can be satisfied by finished products that are distributed by warehouse locations. As constraints (32) allow demands to not be fully covered, delivery shortages are taken into account.

\subsubsection{Material flows}

$$
\begin{gathered}
\sum_{q \in S_{\sigma+1}} x_{g s q t}^{\sigma, \sigma+1} \leq p r_{g s t}^{\sigma}+\gamma_{t} \cdot s t_{g s t}^{\sigma} ; \quad \forall g \in G_{\sigma}, \quad s \in S_{\sigma}, \quad \sigma=2, \ldots, W+1, \\
t=1, \ldots, t_{E}+1 \\
\sum_{q \in S_{\sigma+1}} x_{g s q t}^{\sigma, \sigma+1} \leq \gamma_{t} \cdot s t_{g s t}^{\sigma}+\sum_{q \in S_{\sigma-1}} x_{g q s t}^{\sigma-1, \sigma} ; \quad \forall g \in G_{W+1}, \quad s \in S_{\sigma}, \\
\sigma=W+2, \ldots, W+L+1, \quad t=1, \ldots, t_{E}+1
\end{gathered}
$$

Continuity of material flows: considering plant locations in constraints (33), outgoing quantities of intermediate products or finished products, respectively, cannot exceed the sum of production and storage quantities. The same applies to warehouse locations in (34). In the latter case, ingoing quantities are used instead of production quantities, and finished products are taken into account exclusively. Again, the consideration of storage quantities is excluded for time period $t_{E}+1$.

$$
\begin{aligned}
& \sum_{g \in G_{\sigma}} v_{g}^{\sigma, \sigma+1} \cdot x_{g q s t}^{\sigma, \sigma+1} \leq T C_{q s t}^{\sigma, \sigma+1} \cdot t_{q s t}^{\sigma, \sigma+1} ; \quad \forall q \in S_{\sigma}, \quad s \in S_{\sigma+1}, \quad \sigma=1, \ldots, W, \\
& \quad t=1, \ldots, t_{E}+1
\end{aligned}
$$

$$
\begin{aligned}
& \sum_{g \in G_{W+1}} v_{g}^{\sigma, \sigma+1} \cdot x_{g q s t}^{\sigma, \sigma+1} \leq T C_{q s t}^{\sigma, \sigma+1} \cdot t_{q s t}^{\sigma, \sigma+1} ; \quad \forall q \in S_{\sigma}, \quad s \in S_{\sigma+1}, \\
& \sigma=W+1, \ldots, W+L+1, \quad t=1, \ldots, t_{E}+1
\end{aligned}
$$

Adherence to transportation capacities: if products are transported from one location to another location of a subsequent SC stage, maximum transportation capacities must be considered. This applies to transportation of raw materials and intermediate products [see (35)] and transportation of finished products [see (36)].

\subsection{Binary and non-negativity constraints}

$$
\begin{aligned}
& y_{s t}^{\sigma} \in\{0,1\} ; \quad \forall s \in S_{\sigma}, \quad \sigma \in\{1, W+L+2\}, \quad t=1, \ldots, t_{E}+1 \\
& y_{s k t}^{\sigma \tau} \in\{0,1\} ; \quad \forall s \in S_{\sigma}, \quad k \in K_{\sigma \tau}, \quad \sigma=2, \ldots, W+L+1, \quad \tau \in\{0, \ldots, t\}, \\
& t=1, \ldots, t_{E}+1 \\
& \quad t_{q s t}^{\sigma, \sigma+1} \in\{0,1\} ; \quad \forall q \in S_{\sigma}, \quad s \in S_{\sigma+1}, \quad \sigma=1, \ldots, W+L+1, \\
& \quad t=1, \ldots, t_{E}+1 \\
& o_{s t}^{\sigma}, c_{s t}^{\sigma} \in\{0,1\} ; \quad \forall s \in S_{\sigma}, \quad \sigma=2, \ldots, W+L+1, \quad t=1, \ldots, t_{E}+1
\end{aligned}
$$




$$
\begin{gathered}
p r_{g s t}^{\sigma}, \quad s t_{g s t}^{\sigma} \geq 0 ; \quad \forall g \in G_{\sigma}, \quad s \in S_{\sigma}, \quad \sigma=2, \ldots, W+1, \quad t=1, \ldots, t_{E}+1 \\
s t_{g s t}^{\sigma} \geq 0 ; \quad \forall g \in G_{W+1}, \quad s \in S_{\sigma}, \quad \sigma=W+2, \ldots, W+L+1, \quad \text { (41) } \\
t=1, \ldots, t_{E}+1
\end{gathered}
$$

\section{Model variant based on capacity levels}

Notwithstanding the aforementioned benefits of using capacity profiles (see Sect. 3), a model variant is presented in the following. It alternatively considers capacity levels that allow for leaving the discrete capacity planning completely to the model. Capacity levels are defined as available maximum capacities (e.g., workforce, machines, shelves, etc. that determine the maximum quantity produced or stored at a location within one time period), which are valid for single time periods of the planning horizon and can develop in any sequence. Thus, the assignment of a capacity level is required for each time period the location is available to the network. Modeling requires redefining $k$ as capacity level index $\left(k, \ell \in K_{\sigma}\right)$. It is based on analyzing the relationship between capacity levels selected in two subsequent time periods of the planning horizon. In this context, some of the former binary variables as well as monetary and capacity parameters need to be redefined. Furthermore, a new binary variable $\left(a_{s k \ell t}^{\sigma}\right)$ needs to be introduced in order to indicate changes of the capacity level. It equals 1 if the capacity of plant/warehouse location $s$ of SC stage $\sigma$ is adjusted from level $k$ to level $\ell(k \neq \ell)$ at the beginning of time period $t$, and 0 otherwise. However, the substantial difference in modeling is that the former configuration constraints (14)-(22) must be replaced by the following constraints (48)-(56).

$$
y_{s k t}^{\sigma} \geq o_{s k t}^{\sigma} ; \quad \forall s \in S_{\sigma}, \quad \sigma=2, \ldots, W+L+1, \quad k \in K_{\sigma}, \quad t \in T
$$

According to (48), the opening of a location in a specific capacity level at the beginning of a time period must result in the availability of the location (in the same capacity level) during this time period. Said another way, the location cannot be opened at the beginning of a time period, if it is not available during the same time period. 


$$
\sum_{k \in K_{\sigma}} y_{s k t}^{\sigma}-\sum_{k \in K_{\sigma}} y_{s k, t-1}^{\sigma} \leq \sum_{k \in K_{\sigma}} o_{s k t}^{\sigma} ; \quad \forall s \in S_{\sigma}, \quad \sigma=2, \ldots, W+L+1, \quad t \in T
$$

The binary variable $o_{s k t}^{\sigma}$ within (49) indicates the opening of a plant/warehouse location, if the latter is available in the current time period $t$, but it is not available in the previous time period $t-1$ (regardless of the selected capacity level).

$$
\begin{gathered}
y_{s k, t-1}^{\sigma} \geq c_{s k t}^{\sigma} ; \quad \forall s \in S_{\sigma}, \quad \sigma=2, \ldots, W+L+1, \quad k \in K_{\sigma}, \quad t \in T \\
\sum_{k \in K_{\sigma}} y_{s k, t-1}^{\sigma}-\sum_{k \in K_{\sigma}} y_{s k t}^{\sigma} \leq \sum_{k \in K_{\sigma}} c_{s k t}^{\sigma} ; \quad \forall s \in S_{\sigma}, \quad \sigma=2, \ldots, W+L+1, \quad t \in T
\end{gathered}
$$

Analogously, the closing of a plant/warehouse location at the beginning of time period $t$ in a specific capacity level (that determines the liquidation proceeds) requires that the same location was available in the same capacity level during the previous time period $t-1$ [see (50)]. Regardless of the selected capacity level, the closing additionally requires that the location is no longer available in the current time period $t$ [see (51)].

$$
\begin{gathered}
2-\sum_{k \in K_{\sigma}} y_{s k, t-1}^{\sigma}-\sum_{k \in K_{\sigma}} y_{s k t}^{\sigma} \geq \sum_{k \in K_{\sigma}} o_{s k t}^{\sigma}+\sum_{k \in K_{\sigma}} c_{s k t}^{\sigma} ; \quad \forall s \in S_{\sigma}, \\
\sigma=2, \ldots, W+L+1, \quad t \in T
\end{gathered}
$$

Constraints (52) prevent the binary variables from indicating openings or closings, respectively, if the location is unavailable in both the current and the previous time period.

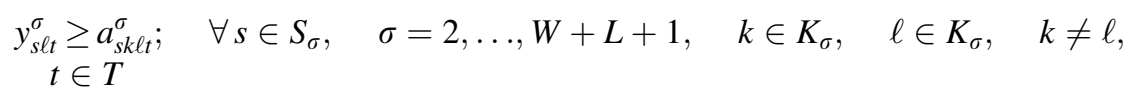

$$
\begin{aligned}
& y_{s k, t-1}^{\sigma} \geq a_{s k \ell t}^{\sigma} ; \quad \forall s \in S_{\sigma}, \quad \sigma=2, \ldots, W+L+1, \quad k \in K_{\sigma}, \quad \ell \in K_{\sigma}, \quad k \neq \ell, \\
& \quad t \in T
\end{aligned}
$$

$$
\begin{aligned}
& y_{s k, t-1}^{\sigma}+y_{s \ell t}^{\sigma}-1 \leq a_{s k \ell t}^{\sigma} ; \quad \forall s \in S_{\sigma}, \quad \sigma=2, \ldots, W+L+1, \quad k \in K_{\sigma}, \quad \ell \in K_{\sigma}, \\
& \quad k \neq \ell, \quad t \in T
\end{aligned}
$$

Capacity adjustments are possible during the availability of locations, i.e., at the beginning of time periods after their opening and before their closing. They require the change of capacity levels. Prerequisites for indicating this change (from level $k$ to $\ell$ ) by a specific binary variable are the availability of the new capacity level $\ell$ during the current time period $t$ [see (53)] and the former availability of a different capacity level $k$ during the previous time period $t-1$ [see (54)]. By the use of (55), the indication of a capacity adjustment by the binary variable is forced, if both conditions are met simultaneously. 


$$
\sum_{k \in K_{\sigma}} y_{s k t}^{\sigma} \leq 1 ; \quad \forall s \in S_{\sigma}, \quad \sigma=2, \ldots, W+L+1, \quad t \in T
$$

Finally, constraints (56) ensure that at least one capacity level can be assigned to a plant or warehouse location within a time period (i.e., capacity levels are mutually exclusive).

The consequences of using the alternative modeling techniques (capacity profiles vs. capacity levels) are analyzed within Sect. 6 for the following case study.

\section{Case study of a sanitary supply chain}

The following case study considers the restructuring and operations of the sanitary company during a 3-year engagement of an institutional investor, which is assumed to start at the beginning of the year 2008. The latter represents the reference date of analysis, as the present value of equity is maximized to determine realizable annual payouts to the investor. In the following, the company's core activities are considered. As company data are treated confidentially in general, we use estimated data.

The underlying SC structure for the production of sanitary fittings includes one supplier stage, one production stage and one distribution stage. The company owns three plant locations in Germany, which manufacture 6 days a week and in three country-specific locations, whereby only one site is currently used as warehouse location. Metal components are obtained from three external suppliers. For the planning three international sales markets are taken into account. Products are categorized in two groups, which are small washstands (product A) and large tubs (product B). Both require similar manufacturing processes, but differ in their material usages and production cash outflows. In particular, the washstands are made of a specific $1-\mathrm{kg}$ brass component (component $\mathrm{X}$ ). The tubs require a different brass component of $2 \mathrm{~kg}$ (component $\mathrm{Y}$ ). Furthermore, the same control lever (product Z) is used in both products. The latter three metal components can be obtained as raw materials from external foundries in Hemer (location 1,1), Hettstedt (location 1,2) and Plettenberg (location 1,3). The production process can be described as follows. After the compounding of suitable copper and zinc alloys, the sanitary fittings are manufactured. Water directing hollow spaces are filled with a quartz sand core using the low-pressure permanent mold casting process (Grote and Antonsson 2009, p. 546). The brass is liquefied at high temperatures (minimum temperature $1000{ }^{\circ} \mathrm{C}$ ) and formed. For the control lever cost-effective zinc alloy is used. At the plant locations in Lahr (location 2,1), Hemer (location 2,2) and Porta Westfalica (location 2,3) the sanitary fittings are assembled, which starts with the mechanic processing of the brass components' surfaces. Therefore, automated mill and drill procedures are implemented. Then, the blank fittings are dragged and polished. A lamination serves to refine the surfaces. During the galvanization in an electrolytic immersion bath, the chromium plating of the brass components is conducted. The final assembly includes the equipping with diverse parts, e.g., plugs, screws and ceramic cartridges, which are omitted in the following consideration. 
The sales of sanitary fittings are coordinated by the warehouse location at Porta Westfalica (location 3,1). Further locations eventually to be used as warehouse locations are situated in Vienna (location 3,2) and Volketswil (location 3,3). There, the fittings can be stored and supplied to different retailers in Germany (location 4,1), Austria (location 4,2) and Switzerland (location 4,3). For capacity adjustment, one of three capacity profiles (capacity extension, capacity stagnation, capacity downsizing) needs to be assigned to each location. According to the maximum throughput of the locations, production and storage capacity usages of one unit and 2.5 units can be calculated for washstands and tubs, respectively. The holding company owned by the institutional investor has access to a financial framework including a maximum individual credit volume of EUR 0.75 million up to a maximum total credit volume of EUR 1 million per year. For financing, the duration dependent standard market interest rates (base interest rate for financing objects) are relevant. Due to the current total debt of the company (being valid at the beginning of time period $\vartheta$, which is equal to the point in time the credit would start), the base interest rates are adjusted by a specific risk premium that is assumed to be calculated by the following function in our case:

$$
i_{\vartheta t}^{F O}\left(\mathrm{DEB}_{\vartheta}\right)=i_{\vartheta t}^{\mathrm{BASE}}+\frac{\mathrm{DEB}_{\vartheta}}{10 \cdot \mathrm{DEB}^{\max }}
$$

Despite the fact that the aforementioned linear assumption with a range of the risk premium between 0 and $10 \%$ is based on rough estimates of experts involved, our non-linear model formulation allows for the use of any other functional relationship in general. References for its determination are provided by Saunders and Schumacher (2000) and D'Auria et al. (1999). The maximum total debt (debt limit) is assumed to be EUR 3 million. As the financial investor is interested in maximizing the company's value of equity, the FTE during his engagement (that are equal to the annual cash outflows to the investor) on the one hand, and the summarized FTE after his engagement (that are determining the residual value, and thus, the selling price) on the other hand, need to be discounted. The discounting rate is calculated according to the CAPM. In particular, the levered beta needs to be applied to capture the company's riskiness of the business it operates in and the amount of financial leverage risk it has taken on (Damodaran 2012).

$$
\begin{gathered}
r^{E Q}=r^{R F}+\left(r^{M A}-r^{R F}\right) \cdot \beta^{\text {lev }} \\
\beta^{\text {lev }}=\beta^{\text {unlev }} \cdot[1+(1-\mathrm{TX}) \cdot \mathrm{DER}]
\end{gathered}
$$

In our case, the calculation is based on the yield expected on long-term risk-free government bonds in January $2008\left(r^{R F}=3.98 \%\right)$ and the expected return on the German stock market in January $2008\left(r^{M A}=9.17 \%\right)$. However, the beta factor cannot be determined by analyzing the company's share prices, since the company was delisted after a previous company takeover in the year 2000. Using a bottom-up unlevered beta (Damodaran 2012) based on the average over 36 companies for metal fabricating in 2008 ( $\beta^{\text {unlev }}=1.1$ ), a levered beta of $\beta^{\text {lev }}=1.84$ results for the considered sanitary company with a debt-equity-ratio of DER $=104 \%$, since an 
average income tax rate of $\mathrm{TX}=35.22 \%$ is valid for it. As a result, $r^{E Q}=13.5 \%$ is obtained.

\section{Application of the model on the sanitary supply chain}

The model (1)-(47) was used to optimize the sanitary supply chain described in Sect. 5. For the computations, a high-performance computer with two Intel Xeon X5690 processors, 12 threads, $3.46 \mathrm{GHz}, 6.4 \mathrm{GT} / \mathrm{s}$ and $192 \mathrm{~GB}$ RAM was used. All calculations were started individually to make use of the full computation capacity. The mixed-integer non-linear programming model was implemented in the optimization software GAMS 23.8. It was computed using the SCIP 2.1.1 solver, which is able to deal with non-linearity by applying an interior point optimizer (GAMS 2012). Differing from the default settings the number of parallel cores to be used by the solver was set to the maximum and the relative MIP gap tolerance was set to $0 \%$. As a result, the optimal solution was found after $31 \mathrm{~s}$. The maximum present value of equity is EUR 448.762 million and the corresponding optimal network configuration is depicted in Fig. 4.

At the beginning of his engagement in 2008, the investor takes decisions on capacity adjustment at the three production locations that are continued from the initial configuration. Whereas technical and personnel capacity of both locations in Lahr und Hemer is extended (starting from 1 Mio. capacity units before the acquisition) during the planning horizon by 0.2 Mio. capacity units per year, capacity downsizing is chosen for the production location in Porta Westfalica (minus 0.2 Mio. capacity units per year). The latter adjustment lasts for 3 years until the location is liquidated at the end of the investor's engagement (i.e., the end of 2010). According to the demand expected for the products offered by the sanitary supply chain, the investor decides to open a new distribution location in Volketswil with constant capacities (i.e., 2 Mio. capacity units are additionally available) at the beginning of 2008, which supplements the stagnating storage capacity (2 Mio. capacity units) of the existing distribution location in Porta Westfalica. Hence, the sanitary company is able to meet the demand at all markets in all time periods completely. For providing essential raw materials, the supplier in Plettenberg is to be used throughout the whole planning horizon. The deliveries are complemented by the supplier in Hettstedt during the year 2009.

Financial effects can be assigned to the beginning of the three time periods of the investor's engagement (beginning of the years 2008, 2009 and 2010), to the end of the last time period of the investor's engagement (end of year 2010) as well as to the end of the following time period (end of year 2011). The latter is assumed to be a representative for all upcoming time periods (see Table 1). As there are no financial obligations of the investor after his engagement (outstanding short-term loans, etc.), the results of 2011 may be repeatable within the company that will have been sold to new holders. As a consequence, a perpetuity (annuity for which the payments continue forever) is considered for this phase. 


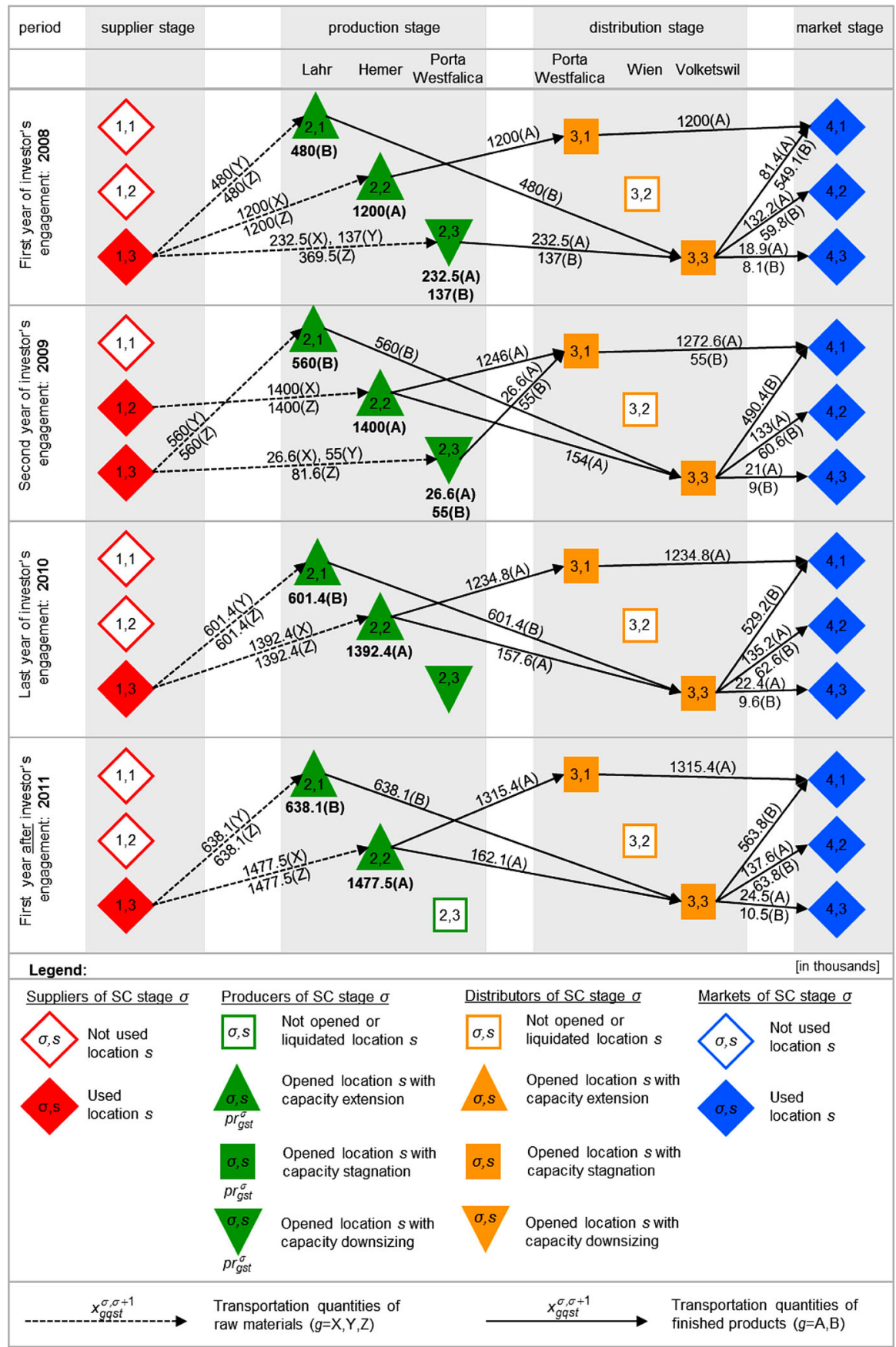

Fig. 4 Optimal supply chain network structure 
Table 1 Calculation of FTE (in EUR million)

\begin{tabular}{|c|c|c|c|c|c|}
\hline & $\begin{array}{l}\text { Beginning } \\
\text { of } 2008\end{array}$ & $\begin{array}{l}\text { Beginning } \\
\text { of } 2009\end{array}$ & $\begin{array}{l}\text { Beginning } \\
\text { of } 2010\end{array}$ & $\begin{array}{l}\text { End of } \\
2010\end{array}$ & $\begin{array}{l}\text { End of } 2011 \text { and } \\
\text { following years }\end{array}$ \\
\hline Operating cash flow & & 93.282 & 95.727 & 89.416 & 95.873 \\
\hline Interest payments for credits & & -0.000 & -0.058 & -0.319 & \\
\hline Taxes (tax rate $35.2 \%$ ) & & -32.835 & -33.676 & -31.362 & -33.747 \\
\hline Net operating profit after taxes & & 60.447 & 61.994 & $\mathbf{5 7 . 7 3 5}$ & 62.125 \\
\hline Credit f12 (interest rate $6.9 \%$ p.a.) & 0.250 & & -0.250 & & \\
\hline Credit f13 (interest rate $6.4 \%$ p.a.) & 0.750 & & & -0.750 & \\
\hline Credit f22 (interest rate $8.7 \%$ p.a.) & & 0.250 & -0.250 & & \\
\hline Credit $\mathrm{f} 23$ (interest rate $6.2 \%$ p.a.) & & 0.750 & & -0.750 & \\
\hline Credit f33 (interest rate $9.5 \%$ p.a.) & & & 0.750 & -0.750 & \\
\hline Location investments & -1.000 & & & & \\
\hline Location disinvestments & & & & 2.700 & \\
\hline Capacity (dis-)investments & -2.175 & -2.000 & -2.000 & -4.000 & \\
\hline FTE & -2.175 & 59.447 & 60.244 & 54.185 & 62.125 \\
\hline
\end{tabular}

At the beginning of the planning horizon, no surpluses from operations are available to the investor. Putting the new distribution location in Volketswil into operation requires EUR 1.175 million (EUR 1 million for opening + EUR 0.175 million for making related capacities available). Furthermore, initial capacity changes (capacity expansions in Lahr and Hemer that require EUR 4 million in each year of the investor's engagement, and can be balanced with annual cash inflows of EUR 2 million resulting from capacity downsizing at the production location in Porta Westfalica until the beginning of 2010) need to be considered. As financing through two credits (summed up to EUR 1 million, which is equal to the credit limit of this period) is not sufficient for the purposes mentioned above, the investor is advised to provide additional funds of EUR 2.175 million to the company to obtain increasing FTEs in the future. The credits must be repaid after 2 years (EUR 0.25 million) and 3 years (EUR 0.75 million), respectively. After the first period (i.e., at the beginning of the year 2009), the net operating profit after taxes is EUR 60.447 million. It is adjusted for regular payments of the aforementioned ongoing capacity changes (balanced to cash outflows of EUR 2 million). Taking into account two new credits (EUR 0.25 million for 1 year and EUR 0.75 million for 2 years, interest rates contain risk premium due to the current total debt of EUR 2 million), a cash outflow to the investor of EUR 59.447 million is possible. After the second time period (i.e., at the beginning of the year 2010) the tax shield becomes relevant for determining the net operating profit after taxes of EUR 61.994 million, as interests of EUR 0.058 million must be paid for two expiring loans (repayment amount of EUR 0.5 million). Simultaneously, a new loan (credit amount of EUR 0.75 million, interest rate $2 \%$ p.a. + risk premium $7.5 \%$ p.a. due to a current total debt of EUR 2.25 million and the debt limit of EUR 3 million) is taken out. The FTE of EUR 60.244 million results. After the following time period, the engagement of the investor ends. Last decisions on the adjustment 
of the network structure are possible at this point in time (end of the year 2010). In particular, there are cash inflows of EUR 2.7 million resulting from the liquidation of the production location in Porta Westfalica. As the rest of the configuration remains untouched (i.e., there are no further closings of locations), ongoing operations are ensured after the investor's engagement. Three outstanding loans (summed up to EUR 2.25 million) are repaid, the related interests (summed up to EUR 0.319 million) are relevant for the calculation of the tax shield. Due to a net operating profit after taxes of EUR 57.735 million, a last cash outflow to the investor of EUR 54.185 million is possible. Using the given network structure that would be available to the new holders after the investor's engagement, a net operating profit after taxes of EUR 62.125 million could be generated per year. As the latter is assumed to be a perpetuity, a residual value of EUR 460.19 million (valid at the end of the year 2010) can be calculated.

The aforementioned optimal solution is based on the assumption that the investor is able and willing to provide additional funds at the beginning of his engagement for restructuring. However, if the investor would only be interested in positive payouts during the engagement (which can easily be implemented by adding nonnegativity constraints for FTE), it can be shown that the company would be cashconstrained, which is preventing potential "growth activities". In particular, the maximum present value of equity would decrease to EUR 431.056 million. Considering the corresponding optimal network structure, the investor would be forced to cease from production in Porta Westfalica with immediate effect. In addition, the opening of the new distribution location in Volketswil must be postponed to the beginning of 2009. Due to the resulting lack of storage capacity, considerable delivery shortages would be expected during the first time period of the investor's engagement-arising especially in the second product group "tubs", moreover, the Swiss market would be completely unsatisfied. Occurring overcapacities at the location in Lahr are used for the production of tubs that are transferred to the second time period by time overlapping storage. Although the demand is expected to be satisfied completely after the first year of the investor's engagement, an overall percentage of demand coverage of $95.1 \%$ results.

Additionally, we tested the alternative model formulation characterized by the usage of capacity levels instead of capacity profiles, which results from implementing the alternative configuration constraints (48)-(56) in the remaining model (1)-(13), (23)-(47) that is adjusted by the capacity level index. With regard to the aforementioned case study, the three former capacity profiles being applicable to all of the locations were split up (according to the given data from the case study) into nine capacity levels for the plant locations and seven capacity levels for the warehouse locations. As expected due to the possibility of selecting any sequences of maximum capacity (which include undesired or even infeasible developments), the computation time drastically increases. Thus, the computation (performed on the same aforementioned hardware and software) was aborted after $24 \mathrm{~h}$. The best present value of equity that was found by then was EUR 454.161 million. However, a huge gap of $734 \%$ was valid at the same time. 


\section{Scenario analysis}

In addition to the case study (see Sect. 6) alternative scenarios were prepared in order to evaluate the stability of the solution. In particular, the consequences of considering different discounting rates, uncertain demand as well as additional sustainability requirements are analyzed. Except the subject of analysis, the test instances of the scenarios are based on the same parameters as in the case study. Moreover, the same high-performance software and hardware with the same settings were used for the computations. As a result, the computation time (CT in seconds), the cash flows to/from the investor during his 3-year engagement $\left(\mathrm{FTE}_{0}, \mathrm{FTE}_{1}\right.$, $\mathrm{FTE}_{2}$ and $\mathrm{FTE}_{3}$ in EUR million), the expected annual cash outflow after his engagement determining the residual value ( $\mathrm{FTE}_{4}$ in EUR million), the present value of equity (VEQ in EUR million) and the overall percentage of demand coverage (COV in \%) were recorded.

The first scenario analysis is related to the challenge of determining accurate discounting rates (to consider the time value of money and risk premium) and the potential impact of misspecified discounting rates on optimal decisions. This is especially important due to the bottom-up beta (see Sect. 5), which is not based on the company's share prices, but on an industry average. For this reason, we created eight test instances with discounting rates that are near to $r^{E Q}$ calculated for the case study (13.5\%). In particular, discounting rates of 13.1-13.4\% were used for the four instances R1 to R4, and discounting rates of 13.6-13.9 \% were used for the other four instances R5 to R8.

Although the discounting rate chosen within the aforementioned intervals determines the present value of equity and the residual value (and thus, the selling price of the company), we found out that it has no impact on the optimal network structure and the FTE realizable (Table 2) during the investor's engagement. As a consequence, slight inaccuracies or uncertainties while calculating the cost of equity can be neglected in our case.

As the capital withdrawal by the investor can easily decrease the flexibility of the SC network, and thus, make it more vulnerable to unexpected changes in the business environment, a second scenario analysis is taken to determine the effects of fluctuations in demand. Instead of the expected demand used in the case study, a uniform integer random number between the following lower and upper bounds was generated by the optimization software $\mathrm{D}_{11 t} \in[1200,1400], \mathrm{D}_{21 t} \in[500,600]$, $\mathrm{D}_{12 t} \in[130,140], \quad \mathrm{D}_{22 t} \in[50,70], \quad \mathrm{D}_{13 t} \in[10,30], \quad \mathrm{D}_{23 t} \in[5,15], \quad \forall t=1, \ldots, 4$ within all of the following 25 test instances (No. D1-D25). The other parameters of the case study remained unchanged. The results are presented in Table 3.

It becomes obvious that the present value of equity is in the range between EUR 427.938 million and EUR 456.654 million. Regardless of the test instance, the company is able to cover more than $99 \%$ (on average more than $99.9 \%$ ) of the overall demand despite the investor's payout claims. All instances were computable without a considerable expenditure of time.

The case study also reveals that supply chain planning is subordinated to the investor's payout claims. This may cause conflict of interests. Thereby, the investor 
Table 2 Scenario analysis 1 -discounting rates

\begin{tabular}{lllllllll}
\hline No. & CT & FTE $_{0}$ & FTE $_{1}$ & FTE $_{2}$ & FTE $_{3}$ & FTE $_{4}$ & VEQ & COV \\
\hline R1 & 24 & -2.175 & 59.447 & 60.244 & 54.185 & 62.125 & 462.737 & 100 \\
R2 & 27 & -2.175 & 59.447 & 60.244 & 54.185 & 62.125 & 459.164 & 100 \\
R3 & 20 & -2.175 & 59.447 & 60.244 & 54.185 & 62.125 & 455.644 & 100 \\
R4 & 15 & -2.175 & 59.447 & 60.244 & 54.185 & 62.125 & 452.177 & 100 \\
R5 & 23 & -2.175 & 59.447 & 60.244 & 54.185 & 62.125 & 445.397 & 100 \\
R6 & 20 & -2.175 & 59.447 & 60.244 & 54.185 & 62.125 & 442.082 & 100 \\
R7 & 21 & -2.175 & 59.447 & 60.244 & 54.185 & 62.125 & 438.815 & 100 \\
R8 & 27 & -2.175 & 59.447 & 60.244 & 54.185 & 62.125 & 435.595 & 100 \\
\hline
\end{tabular}

Table 3 Scenario analysis 2-demand fluctuations

\begin{tabular}{|c|c|c|c|c|c|c|c|c|}
\hline No. & $\mathrm{CT}$ & $\mathrm{FTE}_{0}$ & $\mathrm{FTE}_{1}$ & $\mathrm{FTE}_{2}$ & $\mathrm{FTE}_{3}$ & $\mathrm{FTE}_{4}$ & VEQ & $\mathrm{COV}$ \\
\hline D1 & 15 & -0.100 & 62.333 & 62.452 & 57.811 & 56.335 & 428.239 & 99.5 \\
\hline D2 & 33 & -2.075 & 61.820 & 57.917 & 58.330 & 58.244 & 432.315 & 100 \\
\hline D3 & 19 & -2.175 & 61.854 & 62.620 & 55.673 & 60.692 & 446.482 & 100 \\
\hline D4 & 24 & -2.175 & 61.725 & 61.220 & 58.244 & 62.589 & 456.654 & 100 \\
\hline D5 & 23 & -2.175 & 62.123 & 60.717 & 60.513 & 59.535 & 442.691 & 100 \\
\hline D6 & 43 & -2.100 & 61.730 & 65.381 & 52.324 & 57.140 & 428.307 & 100 \\
\hline D7 & 26 & -2.175 & 61.536 & 63.277 & 55.565 & 58.972 & 437.924 & 100 \\
\hline D8 & 15 & -2.175 & 61.406 & 61.901 & 58.069 & 61.468 & 451.102 & 100 \\
\hline D9 & 24 & -2.175 & 61.541 & 61.127 & 54.130 & 58.414 & 432.450 & 100 \\
\hline D10 & 26 & -2.175 & 56.781 & 60.352 & 56.430 & 60.910 & 441.877 & 100 \\
\hline D11 & 22 & -2.175 & 57.180 & 58.296 & 53.916 & 62.808 & 448.528 & 100 \\
\hline D12 & 19 & -2.100 & 56.584 & 56.610 & 56.277 & 59.812 & 433.202 & 100 \\
\hline D13 & 13 & -0.100 & 54.532 & 64.596 & 63.273 & 56.566 & 427.938 & 99.8 \\
\hline D14 & 22 & -2.175 & 56.463 & 65.170 & 56.274 & 59.191 & 436.517 & 100 \\
\hline D15 & 19 & -2.175 & 56.597 & 63.438 & 58.574 & 61.687 & 449.512 & 100 \\
\hline D16 & 24 & -2.175 & 55.875 & 62.664 & 56.338 & 63.585 & 456.360 & 100 \\
\hline D17 & 24 & -2.175 & 61.231 & 61.017 & 53.595 & 60.530 & 442.449 & 100 \\
\hline D18 & 28 & -2.075 & 60.937 & 59.563 & 56.312 & 58.646 & 433.475 & 100 \\
\hline D19 & 22 & -2.175 & 61.236 & 58.527 & 58.138 & 59.967 & 440.776 & 100 \\
\hline D20 & 16 & -2.175 & 61.106 & 62.811 & 54.460 & 62.464 & 454.119 & 100 \\
\hline D21 & 13 & -2.175 & 60.648 & 61.435 & 57.030 & 59.409 & 438.931 & 100 \\
\hline D22 & 24 & -2.175 & 60.518 & 60.656 & 54.852 & 61.906 & 449.370 & 100 \\
\hline D23 & 16 & -2.075 & 61.017 & 58.235 & 57.567 & 59.156 & 435.955 & 100 \\
\hline D24 & 20 & -2.175 & 60.523 & 57.771 & 59.979 & 61.272 & 447.428 & 100 \\
\hline D25 & 16 & -2.175 & 60.922 & 61.801 & 57.210 & 58.288 & 433.899 & 100 \\
\hline Avg. & 21.84 & -1.991 & 59.929 & 61.182 & 56.835 & 59.983 & 441.060 & $>99.9$ \\
\hline Stand. dev. & 6.61 & 0.570 & 2.400 & 2.374 & 2.394 & 1.959 & 8.901 & 0.1 \\
\hline
\end{tabular}


Table 4 Scenario analysis 3-sustainability

\begin{tabular}{lllllllll}
\hline No. & CT & FTE $_{0}$ & FTE $_{1}$ & $\mathrm{FTE}_{2}$ & $\mathrm{FTE}_{3}$ & $\mathrm{FTE}_{4}$ & VEQ & COV \\
\hline S1 & 20 & -2.175 & 59.440 & 60.212 & 54.168 & 62.111 & 448.645 & 100 \\
S2 & 20 & -2.175 & 59.414 & 60.244 & 54.156 & 62.121 & 448.693 & 100 \\
S3 & 24 & -2.175 & 59.447 & 60.244 & 53.485 & 60.505 & 440.076 & 100 \\
S4 & 41 & -2.175 & 59.286 & 59.938 & 53.036 & 59.995 & 436.806 & 100 \\
\hline
\end{tabular}

faces a trade-off between cash outflows and sustainability requirements. The latter concern the reputation of the company or the quality of products. Both of these aspects can be (additionally to the expected perpetuity of payouts) relevant while negotiating the selling price of the company after the investor's engagement. With regard to the reliability of suppliers, it may be preferable to maintain previous supply relationships. For this reason, we analyze consequences of continuing cooperation with the supplier in Hemer (No. S1) or Hettstedt (No. S2) during the whole planning horizon. Additionally, we focus on the closing of the production location in Porta Westfalica, which would be optimal due to the aforementioned solution at the end of the investor's engagement. In order to prevent the loss of know-how and human capital, the continued operation of the location with capacity downsizing (No. S3) or even capacity stagnation (No. S4) could be taken into account. The results are presented in Table 4 .

Both alternatives regarding supplier selection only result in negligible changes of the present value of equity. Even the considerations with regard to the continued production in Porta Westfalica lead to changes that are in the range of those that may be caused by demand fluctuations. Again, all test instances were swiftly computable.

\section{Conclusion}

The aforementioned case study is a representative of an increasing economic phenomenon. In case that a solvency problem arises, which can either be caused by management failures or the general economic situation, then often institutional investors (e.g., private equity companies) take over well-established businesses for a limited period of time. Therewith, the shareholders connect return expectations, which have to be satisfied by regular payouts taken from profits. Even though there are examples where existing enterprises were closed down after the takeover, the continuation of supply chain operations should be a primary goal in accordance with political and social requests, as it guarantees ongoing returns.

To reach the aforementioned goal, a non-linear flow-to-equity discounted cash flow model for the coordination of the annual payouts to an investor during his engagement with SC planning (i.e., location liquidations and openings, capacity adjustments, sales market and supplier selection, SC operations) and financial planning is proposed in this paper. The two-phase approach additionally considers operations that would be possible by using the network structure resulting at the end 
of the investor's engagement. Our objective (maximization of the present value of equity) also covers the residual value of the expected perpetuity of payouts. In contrast to data-driven approaches that can be found in the literature in this field, we model relevant relationships between annual decisions by a system of interdependent constraints. In particular, these decisions comprise transactions on the capital market that are realistically influenced by the overall debt limit of the company and the current total debt within the time periods of the engagement. Due to changing market situations, duration-dependent interest rates taking into account the specific time periods the transactions start and end are considered. Resulting trade-offs between financing volume, interest payments and tax shield are captured.

It becomes obvious that the problem outlined above is challenging due to its complexity. However, our computations using high-performance software and hardware revealed that the usage of capacity profiles (which represent feasible or even desirable sequences of capacity levels, and are alternatively selectable by the network managers) leads to the fact that the case study of the German sanitary company could be solved to optimality within seconds. The same applies to all of the test instances in our scenario analysis, which was conducted to capture fluctuations in demand, uncertainties in the determination of discounting rates as well as the consideration of sustainability requirements. By implementing one of our aforementioned solutions, it can be supposed that the business problems of the company taken over by the institutional investor could have been prevented or at least mitigated.

Further research can address the following aspects: As far as a reliable estimate is possible, growth rates of the company after the investor's engagement can be taken into account while maximizing the present value of equity within the FTE approach. With respect to the limited access to funds, alternative forms of financing can be added. For capturing international issues of network planning, effects of different exchange rates and customs duties may be included. Considerations on modeling may also focus on the subjectivity of valuation, i.e., the investor's individual decision field and targets. Finally, the coordination of annual decisions resulting from our proposed model with continuous-time short-term planning at the locations can be implemented.

Open Access This article is distributed under the terms of the Creative Commons Attribution 4.0 International License (http://creativecommons.org/licenses/by/4.0/), which permits unrestricted use, distribution, and reproduction in any medium, provided you give appropriate credit to the original author(s) and the source, provide a link to the Creative Commons license, and indicate if changes were made.

\section{References}

Amid, A., S.H. Ghodsypour, and C. O'Brien. 2009. A weighted additive fuzzy multiobjective model for the supplier selection problem under price breaks in a supply chain. International Journal of Production Economics 121(2): 323-332.

Amiri, A. 2006. Designing a distribution network in a supply chain system: Formulation and efficient solution procedure. European Journal of Operational Research 171(2): 567-576. 
Amrani, H., A. Martel, N. Zufferey, and P. Makeeva. 2011. A variable neighborhood search heuristic for the design of multicommodity production-distribution networks with alternative facility configurations. OR Spectrum 33(4): 989-1007.

Arntzen, B.C., G.G. Brown, T.P. Harrison, and L.L. Trafton. 1995. Global supply chain management at Digital Equipment Corporation. Interfaces 25(1): 69-93.

Ashtab, S., R.J. Caron, and E. Selvarajah. 2014. A binary quadratic optimization model for three level supply chain design. Procedia CIRP 17: 635-638.

Azad, N., and H. Davoudpour. 2013. Designing a stochastic distribution network model under risk. The International Journal of Advanced Manufacturing Technology 64(1): 23-40.

Babazadeh, R., J. Razmi, and R. Ghodsi. 2013. Facility location in responsive and flexible sup-ply chain network design (SCND) considering outsourcing. International Journal of Opera-tional Research 17(3): 295-310.

Baud-Lavigne, B., B. Agard, and B. Penz. 2012. Mutual impacts of product standardization and supply chain design. International Journal of Production Economics 135(1): 50-60.

Canel, C., and B.M. Khumawala. 2001. International facilities location-a heuristic procedure for the dynamic uncapacitated problem. International Journal of Production Research 39(17): 3975-4000.

Chakravarty, A.K. 2005. Global plant capacity and product allocation with pricing decisions. European Journal of Operational Research 165(1): 157-181.

Correia, I., T. Melo, and F. Saldanha-da-Gama. 2013. Comparing classical performance measures for a multi-period, two-echelon supply chain network design problem with sizing decisions. Computers and Industrial Engineering 64: 366-380.

D’Auria, C., A. Foglia, and P.M. Reedtz. 1999. Bank interest rates and credit relationships in Italy. Journal of Banking and Finance 23(7): 1067-1093.

Damodaran, A. 2012. Investment valuation. Hoboken: Wiley.

Ernst, D., and J. Häcker. 2012. Applied international corporate finance, 2nd ed. Vahlen: München.

Fleischmann, B., S. Ferber, and P. Henrich. 2006. Strategic planning of BMW's global production network. Interfaces 36(3): 194-208.

Flynn, B., M. Morita, and J. Machuca. 2011. Managing global supply chain relationships. Hershey: Business Science Reference.

GAMS. 2012. GAMS-the solver manuals. Distribution 23.8. Washington: CreateSpace Independent Publishing Platform.

Gardner, J.C., C.B. McGowan, and S.E. Moeller. 2012. Valuing coca-cola using the free cash flow to equity valuation model. Journal of Business and Economics Research 10(11): 629-636.

Grote, K.H., and E.K. Antonsson. 2009. Springer handbook of mechanical engineering. Berlin: Springer.

Guillén-Gosálbez, G., M. Badell, A. Espuña, and L. Puigjaner. 2006. Simultaneous optimization of process operations and financial decisions to enhance the integrated planning/scheduling of chemical supply chains. Computers and Chemical Engineering 30: 421-436.

Hahn, G.J., and H. Kuhn. 2012a. Value-based performance and risk management in supply chains: A robust optimization approach. International Journal of Production Economics 139(1): 135-144.

Hahn, G.J., and H. Kuhn. 2012b. Designing decision support systems for value-based management: A survey and an architecture. Decision Support Systems 53(3): 591-598.

Hinojosa, Y., J. Puerto, and F.R. Fernández. 2000. A multiperiod two-echelon multicommodity capacitated plant location problem. European Journal of Operational Research 123(2): 271-291.

Ho, W., X. Xu, and P.K. Dey. 2010. Multi-criteria decision making approaches for supplier evaluation and selection: A literature review. European Journal of Operational Research 202(1): 16-24.

Jayaraman, V., R. Srivastava, and W.C. Benton. 1999. Supplier selection and order quantity allocation-a comprehensive model. The Journal of Supply Chain Management 35(2): 50-58.

Keyvanshokooh, E., M. Fattahi, S.M. Seyed-Hosseini, and R. Tavakkoli-Moghaddam. 2013. A dynamic pricing approach for returned products in integrated forward/reverse logistics network design. Applied Mathematical Modelling 37(24): 10182-10202.

Koberstein, A., E. Lukas, and M. Naumann. 2013. Integrated strategic planning of global production networks and financial hedging under uncertain demands and exchange rates. BuR-Business Research 6(2): 215-240.

Kouvelis, P., and Rosenblatt, M. J. 2002. A mathematical programming model for global supply chain management-conceptual approach and managerial insights. In Supply chain managementmodels, applications and research directions, ed. J. Geunes, P.M. Pardalos, and H.E. Romeijn, 245-277. Kluwer: Dordrecht. 
Laínez, J.M., G. Guillén-Gosálbez, M. Badell, A. Espuña, and L. Puigjaner. 2007. Enhancing corporate value in the optimal design of chemical supply chains. Industrial and Engineering Chemistry Research 46: 7739-7757.

Lavaja, J., A. Adler, J. Jones, T. Pham, K. Smart, D. Splinter, M. Steele, and M.J. Bagajewicz. 2006. Financial risk management for investment planning of new commodities considering plant location and budgeting. Industrial and Engineering Chemistry Research 45(22): 7582-7591.

Longinidis, P., and M.C. Georgiadis. 2011. Integration of financial statement analysis in the optimal design of supply chain networks under demand uncertainty. International Journal of Production Economics 129(2): 262-276.

Mandl, G., and K. Rabel. 1997. Unternehmensbewertung. Wien: Ueberreuter.

Melo, M.T., S. Nickel, and F. Saldanha-da-Gama. 2005. Dynamic multi-commodity capacitated facility location: A mathematical modeling framework for strategic supply chain planning. Computers and Operations Research 33(1): 181-208.

Melo, M.T., S. Nickel, and F. Saldanha-da-Gama. 2009. Facility location and supply chain management-a review. European Journal of Operational Research 196(2): 401-412.

Morash, E.A., and S.R. Clinton. 1998. Supply chain integration: customer value through collaborative closeness versus operational excellence. Journal of Marketing Theory and Practice 6(4): 104-120.

Ouhimmou, M., S. D’Amours, R. Beauregard, D. Ait-Kadi, and S. Singh Chauhan. 2008. Furniture supply chain tactical planning optimization using a time decomposition approach. European Journal of Operational Research 189(3): 952-970.

Ramezani, M., M. Bashiri, and R. Tavakkoli-Moghaddam. 2013. A new multi-objective stochastic model for a forward/reverse logistic network design with responsiveness and quality level. Applied Mathematical Modelling 37(1-2): 328-344.

Rong, A., R. Akkerman, and M. Grunow. 2011. An optimization approach for managing fresh food quality throughout the supply chain. International Journal of Production Economics 131(1): 421-429.

Sadjady, H., and H. Davoudpour. 2012. Two-echelon, multi-commodity supply chain network design with mode selection, lead-times and inventory costs. Computers and Operations Research 39(7): 1345-1354.

Sahling, F., and A. Kayser. 2016. Strategic supply network planning with vendor selection under consideration of risk and demand uncertainty. Omega 59: 201-214.

Saunders, A., and L. Schumacher. 2000. The determinants of bank interest rate margins: an international study. Journal of International Money and Finance 19(6): 813-832.

Schmidlin, N. 2014. The art of company valuation and financial statement analysis. Chichester: Wiley.

Selim, H., and I. Ozkarahan. 2008. A supply chain distribution network design model: An interactive fuzzy goal programming-based solution approach. The International Journal of Advanced Manufacturing Technology 36(3): 401-418.

Shapiro, J.F. 2004. Challenges of strategic supply chain planning and modeling. Computers and Chemical Engineering 28(6-7): 855-861.

Sharpe, W.F. 1964. Capital asset prices: A theory of market equilibrium under conditions of risk. The Journal of Finance 19(3): 425-442.

Steinrücke, M. 2011. An approach to integrate production-transportation planning and scheduling in an aluminium supply chain network. International Journal of Production Research 49(21): 6559-6583.

Steinrücke, M., and M. Jahr. 2012. Tactical planning in supply chain networks with customer oriented single sourcing. The International Journal of Logistics Management 23(2): 259-279.

Steinrücke, M. 2015. Integrated production, distribution and scheduling in the aluminium industry: A continuous-time MILP model and decomposition method. International Journal of Production Research 53(19): 5912-5930.

Steinrücke, M., and W. Albrecht. 2016. Quantitative decision support for network integration of start-up companies. International Journal of Globalisation and Small Business 8(1): 73-99.

Taaffe, K., and J. Geunes. 2004. Models for integrated customer order selection and requirements planning under limited production capacity. In Supply chain and finance, ed. P.M. Pardalos, A. Migdalas, and G. Baourakis, 315-344. Singapore: Gainesville.

Taaffe, K., J. Geunes, and H.E. Romeijn. 2008. Target market selection and marketing effort under uncertainty-the selective newsvendor. European Journal of Operational Research 189(3): 987-1003.

Tofighi, S., S.A. Torabi, and S.A. Mansouri. 2016. Humanitarian logistics network design under mixed uncertainty. European Journal of Operational Research 250(1): 239-250. 
Van Roy, T.J., and D. Erlenkotter. 1982. A dual-based procedure for dynamic facility location. Management Science 28(10): 1091-1105.

Wilhelm, W., D. Liang, B. Rao, D. Warrier, X. Zhu, and S. Bulusu. 2005. Design of international assembly systems and their supply chains under NAFTA. Transportation Research Part E 41(6): 467-493.

Yi, G., and G.V. Reklaitis. 2004. Optimal design of batch-storage network with financial transactions and cash flows. AIChE Journal 50(11): 2849-2865. 